\title{
Baseline Estimate of the Retained Gas Volume in Tank 241-C-106
}

C.W. Stewart

G. Chen

June 1998

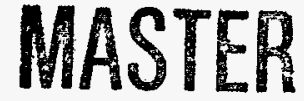

Prepared for

the U.S. Department of Energy

under Contract DE-AC06-76RLO 1830

DISTRIBUTION OF THIS DOCUMENT IS UNLIMITED

Pacific Northwest National Laboratory

Richland, Washington 99352 


\section{DISCLAIMER}

This report was prepared as an account of work sponsored by an agency of the United States Government. Neither the United States Government nor any agency thereof, nor any of their employees, make any warranty, express or implied, or assumes any legal liability or responsibility for the accuracy, completeness, or usefulness of any information, apparatus, product, or process disclosed, or represents that its use would not infringe privately owned rights. Reference herein to any specific commercial product, process, or service by trade name, trademark, manufacturer, or otherwise does not necessarily. constitute or imply its endorsement, recommendation, or favoring by the United States Government or any agency thereof. The views and opinions of authors expressed herein do not necessarily state or reflect those of the United States Government or any agency thereof. 


\section{DISCLAIMER}

Portions of this document may be illegible electronic image products. Images are produced from the best available original document. 


\section{Abstract}

This report presents the results of a study of the retained gas volume in Hanford Tank 241-C-106 (C-106) using the barometric pressure effect method. This estimate is required to establish the baseline conditions for sluicing the waste from C-106 into AY-102, scheduled to begin in the fall of 1998. The barometric pressure effect model is described, and the data reduction and detrending techniques are detailed. Based on the response of the waste level to the larger barometric pressure swings that occurred between October 27, 1997, and March 4, 1998, the best estimate and conservative (99\% confidence) retained gas volumes in C-106 are $24 \mathrm{scm}$ ( $840 \mathrm{scf}$ ) and $50 \mathrm{scm}(1770 \mathrm{scf})$, respectively. This is equivalent to average void fractions of 0.025 and 0.053 , respectively. 



\section{Summary}

This report is designed to provide the baseline retained gas inventory in Hanford Tank 241-C-106 (C-106) as required by the Process Control Plan. The retained gas volume can be estimated by several methods: local measurements by the void fraction instrument (VFI) or retained gas sampler (RGS), correlation of waste surface level fluctuations due to barometric pressure effects (BPE), or surface level rise. Each of these methods has significant uncertainties and limitations on its usefulness. The BPE model assumes gas stored in the waste compresses and expands in response to changes in barometric pressure and computes the gas volume from the correlation of waste level changes and barometric pressure fluctuation. Where applicable, the BPE method senses all the gas in the tank, even if it is not stored uniformly. Considering all factors, the BPE method is the only practicable method available to quantify the gas inventory in C-106 before sluicing.

Obtaining a baseline for the retained gas inventory in C-106 using the BPE method requires level measurements to be taken during the winter months when barometric pressure variations are the greatest. The level changes created by the small expected gas volume can be detected only with the highest pressure change. Waste level and barometric pressure data were obtained for October 27, 1997 to March 4, 1998. Five significant barometric pressure swings were identified that correlated well with waste level changes.

The waste level measurement was made with the digital signal taken directly from the Enraf ${ }^{(8)}$ level gauge. The precision of the digital data has been estimated as \pm 0.004 inches, but the recording logic uses a "delta band" of 0.01 inches, which dominates the actual uncertainty of the measurement. The polling frequency of one minute created a huge volume of quite "noisy" data that required a major effort to reduce. The data reduction was somewhat complicated by the high evaporation rate and periodic makeup water additions. The evaporative level decrease was not linear, and the normal linear detrending model had to be replaced by a quadratic model. Nevertheless, the resulting reduced data had a total uncertainty band of about \pm 0.01 inches.

The level/pressure correlation slopes, $\mathrm{dL} / \mathrm{dP}$, for the five pressure swings were averaged to obtain a best estimate, and a conservative estimate representing the $99 \%$ confidence level was formed by adding three standard deviations of the five values about their mean. The best-estimate and conservative values of the $\mathrm{dL} / \mathrm{dP}$ correlation for $\mathrm{C}-106$ are -0.037 and $-0.079 \mathrm{~cm} / \mathrm{kPa}$, respectively. This gives the best estimate and conservative void fractions as 0.025 and 0.053 and corresponding standard retained gas volumes of $24 \mathrm{scm}(840 \mathrm{scf})$ and $50 \mathrm{scm}(1770 \mathrm{scf})$, respectively.

The analyses in the Flammable Gas topical report for the W-320 project (Pasamehmetoglu et al. 1997) assumed a best-estimate void fraction of $\leq 0.07$ with a bounding value of 0.15 . Since the conservative estimate of the void fraction in the current analysis is only 0.053 , which is well below Los Alamos National Laboratory's best estimate, we conclude that the strategy for controlling flammable gas accumulation and release in the Process Control Plan is conservative. 



\section{Contents}

Abstract................................................................................. iii

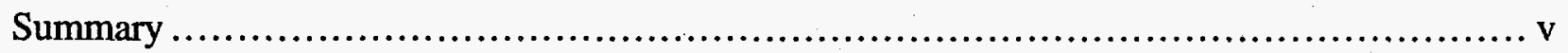

1.0 Introduction. ....................................................................... 1.1

2.0 Retained Gas Volume Calculation Model ..............................................2.1

2.1 The Barometric Pressure Effect Model...............................................2.1

2.1.1 Applicability of the BPE Method to C-106 and AY-102 ........................2.2

2.1.2 Minimum Gas Detection Limits.............................................. 2.3

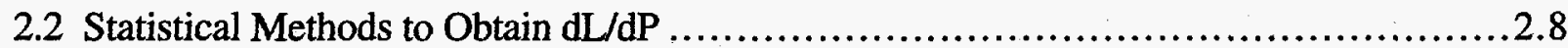

2.3 Reduction of Raw Level Data ......................................................

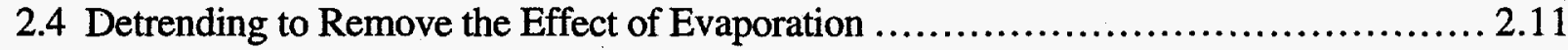

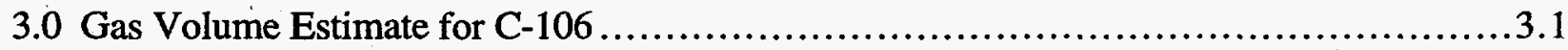

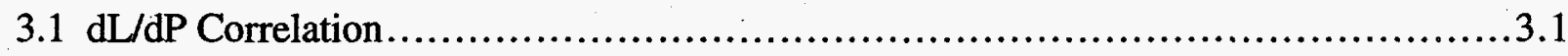

3.1.1 Selection of Barometric Pressure Intervals..................................... 3.1

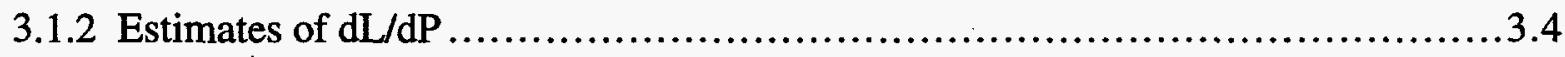

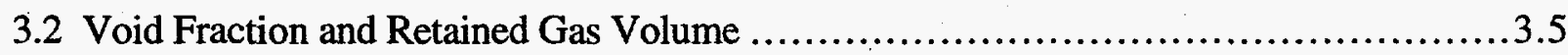

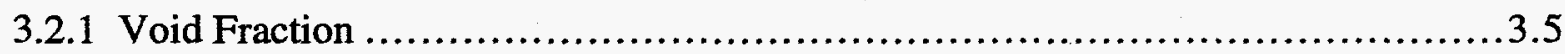

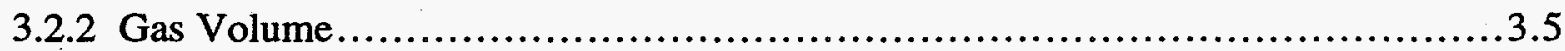

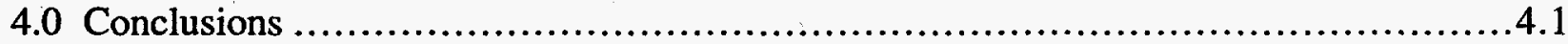

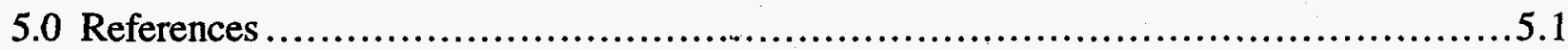




\section{Figures}

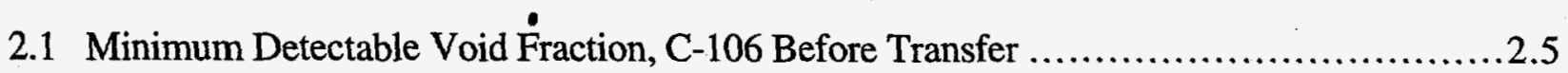

2.2 Minimum Detectable Void Fraction, AY-102 Before Transfer ............................ 2.5

2.3 Fraction of Water Vapor in Gas Bubbles.............................................. 2.7

2.4 Waste Level Versus Pressure Parallelogram.......................................... 2.8

2.5 Raw Analog Level Data from C-106_Stairstep View ............................ 2.10

2.6 Raw Digital Level Data from C-106-Stairstep View ............................. 2.10

2.7 Close-up of C-106 Raw Digital Level Data .................................... 2.11

2.8 Reduced C-106 Digital Level Data-Stairstep View ................................... 2.12

2.9 Reduced Digital Level Data for C-106, 10/28/97-3/4/98........................... 2.12

2.10 Segment of Detrended Level Data for C-106 .................................... 2.13

2.11 Detrended Level Data for C-106, 10/27/97-3/4/98 .............................. 2.14

3.1 Barometric Pressure, 10/27/98-2/28/98............................................. 3.2

3.2 Inverse Pressure-Level Correlation, 10/30/97-11/5/97 ................................ 3.2

3.3 Inverse Pressure-Level Correlation, 12/7/97-12/15/97 .................................3.3

3.4 Inverse Pressure-Level Correlation, 12/16/97-12/22/98 ................................3.3

3.5 Inverse Pressure-Level Correlation, $2 / 19 / 97-3 / 2 / 98$..................................... 3.4

\section{Tables}

1.1 Presluicing Flammable Gas Baseline............................................... 1.2

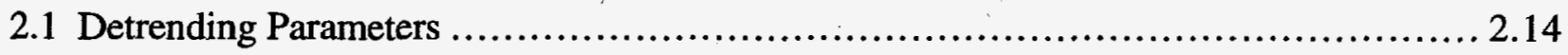

3.1 Selected Barometric Pressure Intervals............................................. 3.1

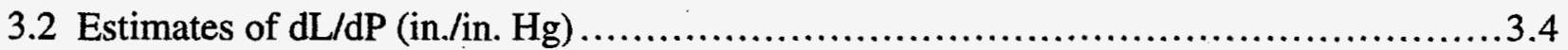

3.3 Summary of Gas Volume Calculations................................................ 


\subsection{Introduction}

The waste in single-shell Tank 241-C-106 (C-106) is planned to be retrieved by sluicing and transferred to double-shell Tank 241-AY-102 (AY-102) in the fall of 1998 under Project $\mathrm{W}-320$. The objective of the transfer from C-106 to AY-102 is to resolve the high-heat safety issue in C-106 and to demonstrate single-shell tank (SST) waste retrieval technology. A major issue involved in the transfer is preventing flammable gas accumulation and release in AY-102 and monitoring and controlling the slurry transport process to ensure this.

The flammable gas safety issue and the strategy for controlling it during and after sluicing have been thoroughly documented. The flammable gas hazards are described and assessed in a topical report by Pasamehmetoglu et al. (1997). The expected conditions during transfer and the process control strategy are given in the Project W-320 Process Control Plan (Carothers et al. 1998). The methods for using the instrumentation available in both AY-102 and C-106 and some additional options for monitoring flammable gas retention and slurry transport are described in Stewart et al. (1997).

All radioactive waste generates flammable gases, mostly hydrogen, with lesser amounts of nitrous oxide, ammonia, and nitrogen. The gas mixture is usually released continuously into the tank headspace at about the same rate as it is generated-where concentrations are kept low by passive or active ventilation (Wilkins et al. 1997). However, if the waste accumulates gas and the tank has a deep layer of supernatant liquid, there is a potential for a buoyant displacement gas release that could create flammable concentrations in the headspace (Meyer et al. 1997). After transfer, the waste in AY-102 will have a relatively high gas generation rate and a deep supernatant layer. Therefore, although neither AY-102 nor C-106 has shown it, significant gas retention and release is theoretically possible and the tank must be monitored during and after sluicing to detect and mitigate any unanticipated gas retention before large releases can occur.

In the current configuration, Tanks C-106 and AY-102 generate relatively low rates of hydrogen and exhibit relatively small retained gas inventories. It is estimated that $\mathrm{C}-106$ generates $0.2 \pm 0.01 \mathrm{~m}^{3} /$ day $\left(6.5 \pm 0.2 \mathrm{ft}^{3} /\right.$ day $)$ of hydrogen, based on the results of a process test conducted in the tank in June 1997 (Jones 1997), and AY-102 an estimated $0.4 \pm 0.2 \mathrm{~m}^{3} /$ day ( $14 \pm 6 \mathrm{ft}^{3} /$ day) based on vapor grab sample analyses and dome hydrogen concentrations from the standard hydrogen monitoring system (SHMS). The best-estimate hydrogen concentration in the waste gas is 60 vol\% in C-106 and $\sim 100$ vol\% in AY-102. In comparison, SY-101 generates about $3 \mathrm{~m}^{3}$ per day (100 $\mathrm{ft}^{3} /$ day) of gas, of which about $30 \%$ is hydrogen.

Both tanks appear to be at,steady state, where the gas generation is equal to the release rate. The transfer of C-106 sludge to AY-102 will cause an increase in the hydrogen generation rate for AY-102 that is expected to be approximately equal to the sum of the current rates. The gas generation rate and gas inventory in C-106 are expected to decrease to near zero by the completion of retrieval. Conversely, gas generation in AY-102 is expected to increase as retrieval progresses. The gas inventory in AY-102 is expected to continue to increase to some new steady-state volume after retrieval is completed. However, uncertainties in both the parameters contributing to gas generation and the waste properties during and after the retrieval give rise to widely varying predictions of waste behavior. 
It is important to know the retained gas inventory in both tanks before sluicing to predict the potential for gas retention after sluicing. As specified in the Tank Waste Remediation System Basis for Interim Operation (F!DH 1997), a presluicing flammable gas baseline will be established for both tanks using a minimum four-week monitoring period to comply with the FDH 1997 safety analysis requirements. Table 1.1 lists the parameters to be established during the baseline period.

The purpose of this report is to provide the required baseline retained gas inventory in C-106 as indicated by the shading in Table 1.1. Retained gas estimates can be made by several methods: local measurements by the void fraction instrument (VFI) or retained gas sampler (RGS), correlation of waste surface level to barometric pressure fluctuations, and surface level rise. Each of these methods has significant uncertainties and limitations on its usefulness. Considering all factors, the barometric pressure effect (BPE) method has been chosen as the most suitable to quantify the gas inventory in C-106 prior to sluicing (Stewart et al. 1997). The surface level rise method and, optionally, local measurements with the VFI are best for assessing gas retention in AY-102 after sluicing.

Obtaining a baseline for the retained gas inventory in C-106 using the BPE method requires measurements to be taken during the winter months when barometric pressure variations are the greatest. Starting up the sluicing process during the summer or early fall requires using the best

Table 1.1. Presluicing Flammable Gas Baseline

\begin{tabular}{|c|c|c|c|}
\hline $\begin{array}{l}\text { Control } \\
\text { Parameter }\end{array}$ & \begin{tabular}{|l|} 
Expected \\
Value $^{(a)}$
\end{tabular} & Instrument & Method to Determine \\
\hline $\begin{array}{l}\text { Flammable gas release } \\
\text { rate for } \mathrm{C}-106\end{array}$ & $\begin{array}{l}0.2 \pm 0.01 \mathrm{~m}^{3} / \mathrm{d} \\
(6.5 \pm 0.2 \mathrm{scf} / \mathrm{d}) \\
\mathrm{H}_{2}\end{array}$ & $\begin{array}{l}\text { SHMS, vent flow } \\
\text { rate }\end{array}$ & $\begin{array}{l}\text { Mathematical integration of } \\
\text { hydrogen concentration over } \\
\text { time }\end{array}$ \\
\hline $\begin{array}{l}\text { Gas composition for } \\
\text { C-106 }\end{array}$ & $\begin{array}{l}\mathrm{H}_{2}-50 \% \\
\mathrm{~N}_{2} \mathrm{O}-15 \% \\
\mathrm{~N}_{2}-9 \% \\
\mathrm{NH}_{3}-3 \% \\
\mathrm{CH}_{4}-2 \% \\
\mathrm{H}_{2} \mathrm{O}-10 \%\end{array}$ & $\begin{array}{l}\text { Grab samples from } \\
\text { SHMS cabinets }\end{array}$ & $\begin{array}{l}\text { Air is mathematically } \\
\text { subtracted using argon as tie } \\
\text { element }\end{array}$ \\
\hline $\begin{array}{l}\text { Retained gas inventory } \\
\text { for C-106 }\end{array}$ & $\frac{\left(268 \mathrm{~m}^{3}\right.}{\left(2,400 \mathrm{f}^{3}\right)}$ & $\begin{array}{l}\text { Enraf surface level } \\
\text { Manford weather } \\
\text { station data }\end{array}$ & Estimate with BPE method \\
\hline $\begin{array}{l}\text { Flammable gas release } \\
\text { rate for AY-102 }\end{array}$ & $\begin{array}{l}0.4 \pm 0.2 \mathrm{~m}^{3} / \mathrm{d} \\
(14 \pm 6 \mathrm{scf} / \mathrm{d}) \mathrm{H}_{2}\end{array}$ & $\begin{array}{l}\text { SHMS, vent flow } \\
\text { rate }\end{array}$ & $\begin{array}{l}\text { Mathematical integration of } \\
\text { hydrogen concentration over } \\
\text { time }\end{array}$ \\
\hline $\begin{array}{l}\text { Gas composition for } \\
\text { AY }-102\end{array}$ & $\mathrm{H}_{2}-100 \%$ & $\begin{array}{l}\text { Grab samples from } \\
\text { SHMS cabinets }\end{array}$ & $\begin{array}{l}\text { Air is mathematically } \\
\text { subtracted using argon as tie } \\
\text { element }\end{array}$ \\
\hline $\begin{array}{l}\text { Retained gas inventory } \\
\text { for A Y } 102\end{array}$ & $\leq 11 \cdot \mathrm{in}(380 \mathrm{ft})$ & $\begin{array}{l}\text { Enraf surface level, } \\
\text { MiT temperature } \\
\text { profle (onee } \\
\text { instailed) }\end{array}$ & $\begin{array}{l}\text { Confinn that no significant } \\
\text { increase m retained gas } \\
\text { volume has occurred }\end{array}$ \\
\hline
\end{tabular}


possible estimates of gas inventory obtained during the previous winter and determining whether major changes might have occurred prior to sluicing startup. The retained gas volume in AY-102 is far below the detection limit of the BPE method, especially given only daily level readings. The gas volume baseline will therefore only confirm, from other indirect data such as waste level changes and MIT temperature profiles, that the gas volume has not increased measurably. This analysis will be performed during the normal baseline period and is not considered here.

This report describes the methods used and the results obtained to determine the baseline gas volume in C-106. Section 2 describes the BPE method for flammable gas retention, including the statistical techniques used to compute the level/pressure correlation, raw level data reduction, and detrending. Section 3 discusses the application of the BPE method to C-106 and the resulting gas volume estimate. Conclusions from this work are stated in Section 4, and the cited references are listed in Section 5. 


\subsection{Retained Gas Volume Calculation Model}

Retained gas volume can be estimated by several methods: local measurements by the VFI or RGS, correlation of waste surface level fluctuations due to BPE, and surface level rise. Each of these methods has significant uncertainties and limitations on its usefulness.

The VFI makes measurements of local gas fraction at about 30-cm (12-inch) vertical spacing at two or three positions on a circle of $0.8 \mathrm{~m}(2.5 \mathrm{ft})$ radius about the centerline of a riser. The average of these measurements is used to estimate the average gas fraction in the entire tank. This requires that the VFI be deployed in at least two risers that are far from the tank wall to give a representative average. The VFI is not an option in C-106 because no suitable risers are available.

The RGS measures the gas fraction in one segment of a 48-cm (19-inch) core sample obtained along the centerline of a riser. As in the case of the VFI, the average gas fraction in the segments obtained is assumed to be the average over the entire tank. Since the waste depth in C-106 allows only three segments, this assumption would be of doubtful validity. More importantly, there are no risers under which the waste has not been disturbed recently by sampling or other operations. Therefore, the RGS is not suitable to measure retained gas volume in C-106.

The surface level rise method assumes (with some corrections) that an increase in waste surface level is due to gas accumulation in the waste. The in situ gas volume is estimated directly from the amount of rise. This is a very robust and accurate method to measure changes in gas inventory nonintrusively. Unfortunately, the need to add water to make up for evaporation in C106 completely masks the small, long-term surface level changes that might indicate gas accumulation.

Gas stored in the waste compresses and expands in response to changes in barometric pressure, causing the waste level to rise and fall. The BPE model computes the gas volume from the correlation of waste level changes and barometric pressure fluctuation. The BPE method, where applicable, senses all the gas in the tank, even if it is stored nonuniformly. While nonintrusive, it has a major disadvantage of a rather large minimum detection limit and requires large barometric pressure changes for good accuracy. However, considering all factors, the BPE method is the only practicable method available to quantify the gas inventory in C-106 before sluicing (Stewart et al. 1997). The balance of this section will describe the model, its limits of applicability, and the data reduction procedures required to determine the correlation between barometric pressure and waste level.

\subsection{The Barometric Pressure Effect Model}

A rigorous derivation of the BPE model is given in Meyer et al. (1997). The resulting model for the gas volume fraction and in situ retained gas volume are described by the following equations:

$$
\alpha=-\frac{\mathrm{p}_{\mathrm{G}}}{\mathrm{L}_{\mathrm{G}}} \frac{\mathrm{dL} \mathrm{w}_{\mathrm{w}}}{d \mathrm{p}_{0}}
$$




$$
\mathrm{V}_{\mathrm{G}}=-\mathrm{Ap}_{\mathrm{G}} \frac{\mathrm{dL}_{\mathrm{w}}}{\mathrm{dp}_{0}}
$$

where $\mathrm{L}_{\mathrm{G}}$ is the average thickness of the gas-bearing waste layer; $\mathrm{A}$ is the tank area; $\mathrm{dL}_{\mathrm{w}} / \mathrm{dp}_{0}$ is the response of the waste surface level, $\mathrm{L}_{\mathrm{w}}$, to barometric pressure changes; and $\mathrm{p}_{\mathrm{G}}$ is the average pressure computed from the hydrostatic head at the midpoint of the waste where the gas is stored. It is computed by

$$
\mathrm{p}_{\mathrm{G}}=\mathrm{p}_{0}+\rho_{\mathrm{SN}} \mathrm{gH} \mathrm{SN}_{\mathrm{SN}}+\rho_{\mathrm{NC}} \mathrm{gH}_{\mathrm{NC}} / 2
$$

where $p_{0}$ is current barometric pressure; $\rho_{\mathrm{SN}}$ and $\rho_{\mathrm{NC}}$ are the densities; and $\mathrm{H}_{\mathrm{SN}}$ and $\mathrm{H}_{\mathrm{NC}}$ are the heights of the supernatant and nonconvective layers, respectively. Note that $\mathrm{H}_{\mathrm{SN}}$ can be replaced with $\mathrm{L}_{\mathrm{w}}-\mathrm{H}_{\mathrm{NC}}$. The gas pressure is currently about $1.1 \mathrm{~atm}$ in C-106 and about $1.8 \mathrm{~atm}$ in AY-102. The standard gas volume, $\hat{\mathrm{V}}_{\mathrm{G}}$, is derived from the in situ volume by correcting to standard pressure and temperature:

$$
\hat{\mathrm{V}}_{\mathrm{G}}=\frac{\mathrm{p}_{\mathrm{G}}}{\hat{\mathrm{p}}} \frac{\hat{\mathrm{T}}}{\mathrm{T}_{\mathrm{G}}} \mathrm{V}_{\mathrm{G}}
$$

where $\hat{p}$ is standard atmospheric pressure $(101,320 \mathrm{~Pa}), \hat{\mathrm{T}}$ is standard temperature $(298 \mathrm{~K}), \mathrm{T}_{\mathrm{G}}$ is the average temperature of the stored gas, and $V_{G}$ is computed from Eq. (2.2).

\subsubsection{Applicability of the BPE Method to C-106 and AY-102}

The assumptions made in the derivation given by Meyer et al. (1997) are summarized:

1. The gas-bearing waste is contained entirely in a cylinder of fixed radius and uniform but temporally variable height (true if waste has a relatively uniform depth and gas fraction or is covered with a liquid layer).

2. The process of expansion and compression due to barometric pressure fluctuation is isothermal (true for expected large gas surface-to-volume ratio on the time scale of barometric pressure changes).

3. The gas stored in the waste behaves as an ideal gas (true for small pressure changes and relatively low temperatures and local pressures with the expected gas composition).

4. The local pressure of all the gas in the waste changes as the barometric pressure (true for relatively weak waste in which the gas elevation does not change measurably with pressure).

5. Vertical waste configuration and in situ gas volume distribution can be estimated or is known to within an appropriate level of uncertainty (true for C-106 and AY-102).

6: The local pressure is radially and azimuthally uniform, or the radial and azimuthal variation of the pressure and gas fraction are uncorrelated (true if assumption 4 is met).

From these assumptions it can be inferred that the BPE model should not be applied to the following types of tanks without very careful consideration: 
- tanks in which a high lithostatic load results from an interstitial liquid level well below the waste surface, where the gas is stored as pore-filling bubbles (potentially violates assumptions 1 and 4)

- tanks with a very low waste level (potentially violates assumption 1)

- t tanks that have been salt-well pumped (potentially violates assumptions 1,4 , and 5)

- tanks with much suspended hardware such as airlift circulators, cooling coils, etc. (potentially violates assumptions 1 and 4)

- tanks in which the waste is periodically disturbed by mixing, specifically SY-101 (violates assumption 4)

- tanks in which the gas elevation (i.e., pressure) changes during the time of the barometric pressure response determination (violates assumption 5)

- tanks in which an appropriately precise waste level instrument is not available, or readings are not taken with sufficient frequency.

The best prospects for an accurate volume determination with the BPE model are tanks with relatively deep, wet waste, where the vertical gas distribution can be estimated with fair confidence. Currently, this includes the double-shell tanks and few of the SSTs.

The BPE method is also applicable to C-106. The waste in C-106 is covered with a shallow supernatant layer and is undisturbed except for periodic water additions to make up for evaporation. Though its rheology has not been measured, the waste appeared to have a muddy consistency when the surface was uncovered during the 1992 process test. This is consistent with descriptions of core samples. It can be assumed that, except for the thin "hardpan" layer in the dish bottom, the waste is relatively weak. Also, with only two meters of waste, the lithostatic pressure is low and gas is expected to exist as discrete bubbles (Gauglitz et al. 1996). The waste level is measured by an Enraf buoyancy gauge to high accuracy, and data are recorded at very high frequency.

The only factors that potentially compromise application of the BPE method in C-106 are the potentially insufficient retained gas volume to detect accurately and errors due to water vapor pressure at the relatively high waste temperature. These problems are addressed in the next section.

\subsubsection{Minimum Gas Detection Limits}

The advantage of the BPE calculation is that it is not affected by evaporation or other cumulative uncertainty. However, it is subject to uncertainty in the gas pressure and to errors due to the limited range of barometric pressure fluctuations and the precision of the level instruments. It is essential that the response of the waste surface is measured precisely and frequently.

A minimum detectable volume can be derived based on a given gas volume uncertainty threshold and level measurement error. The barometric response in Eq. (2.1) can be rewritten in finite difference form as

$$
\mathrm{V}_{\mathrm{G}}=-\mathrm{Ap}_{\mathrm{G}} \frac{\Delta \mathrm{L}_{\mathrm{W}}}{\Delta \mathrm{P}}
$$


where $\Delta \mathrm{L}_{\mathrm{W}}$ is the specific level change in response to a corresponding barometric pressure change of $\Delta \mathrm{P} .{ }^{\left({ }^{2}\right)}$ Assuming the barometric pressure change and tank area are given (i.e., not subject to uncertainty), the relative uncertainty in the retained gas volume in Eq. (2.4) can be estimated approximately by linear error propagation as

$$
\left(\frac{\sigma_{V}}{v_{G}}\right)^{2}=\left(\frac{\sigma_{p}}{p_{G}}\right)^{2}+\left(\frac{\Delta L_{\text {min }}}{\Delta L_{W}}\right)^{2}
$$

where higher-order terms have been ignored. Also, the relative uncertainty in level response has been approximated by the instrument precision divided by the actual level change. The level change is related to the gas volume and barometric pressure change through Eq. (2.4). Solving Eq. (2.4) for $\Delta \mathrm{L}_{\mathrm{w}}$ and substituting the result in Eq. (2.5) yields

$$
\left(\frac{\sigma_{V}}{v_{G}}\right)^{2}=\left(\frac{\sigma_{p}}{p_{G}}\right)^{2}+\left(\frac{A_{P_{G}} \Delta L_{\min }}{v_{G} \Delta P}\right)^{2}
$$

We seek the minimum gas volume that can be determined with an acceptably low error with a given level measurement sensitivity, gas pressure, and range of barometric pressure fluctuation. This can be accomplished by specifying the left side of Eq. (2.6) and solving for $V_{G}$ to yield

$$
\mathrm{V}_{\mathrm{MIN}}=\operatorname{Ap}_{\mathrm{G}} \frac{\Delta \mathrm{L}_{\min }}{\Delta \mathrm{P}\left[\left(\frac{\sigma_{\mathrm{V}}}{\mathrm{V}_{\mathrm{G}}}\right)^{2}-\left(\frac{\sigma_{\mathrm{p}}}{\mathrm{P}_{\mathrm{G}}}\right)^{2}\right]^{1 / 2}}
$$

$\mathrm{V}_{\mathrm{MN}}$ is the minimum in situ gas volume that is measurable with the given uncertainties in volume and pressure and the given instrument precision. Note that the constraint imposed by Eq. (2.5) must be maintained to keep the denominator of Eq. (2.7) positive.

Figures 2.1 and 2.2 show the detectable void fraction as a function of barometric pressure change for waste configurations representing existing conditions in C-106 and AY-102, respectively. In each plot an Enraf level gauge with a precision of $0.5 \mathrm{~mm}$ is assumed (digital signal processing). A qualitative indication of stored gas is deemed practical between 100 and $25 \%$ uncertainty, and good quantitative estimates of gas volume are possible if the volume uncertainty is less than $25 \%$. The nominal barometric pressure change is about $1 \mathrm{kPa}(0.3 \mathrm{in}-\mathrm{Hg}, 0.14 \mathrm{psi})$, with a maximum of $3 \mathrm{kPa}(0.9 \mathrm{in} . \mathrm{Hg}, 0.4 \mathrm{psi})$ in the winter and a minimum of $0.3 \mathrm{kPa}$ (0.09 in. Hg, 0.04 psi) in the summer (Whitney 1995).

(a) The pressure fluctuation should be only the amount that exceeds twice the yield stress of the material, according to Whitney et al. (1996). But the yield stress in C-106 and AY-102 is expected to be small, $150 \mathrm{~Pa}$, compared to barometric pressure changes, which typically exceed $1000 \mathrm{~Pa}$. 


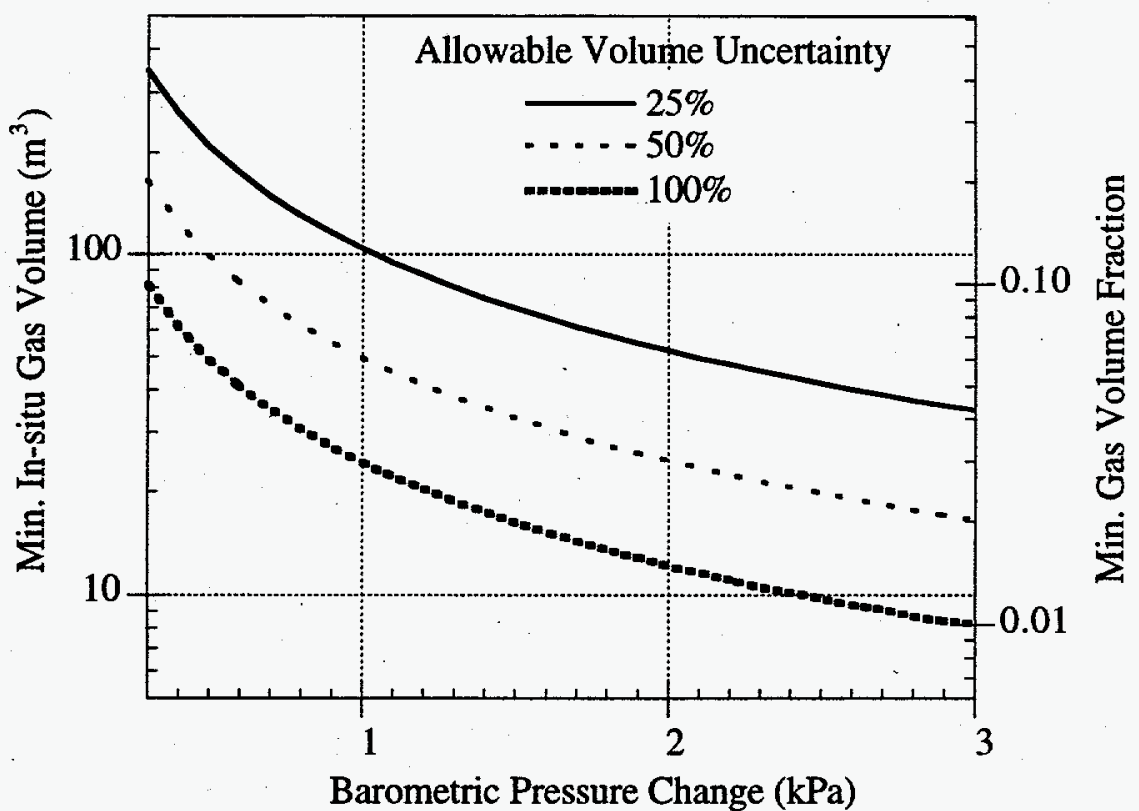

Figure 2.1. Minimum Detectable Void Fraction, C-106 Before Transfer

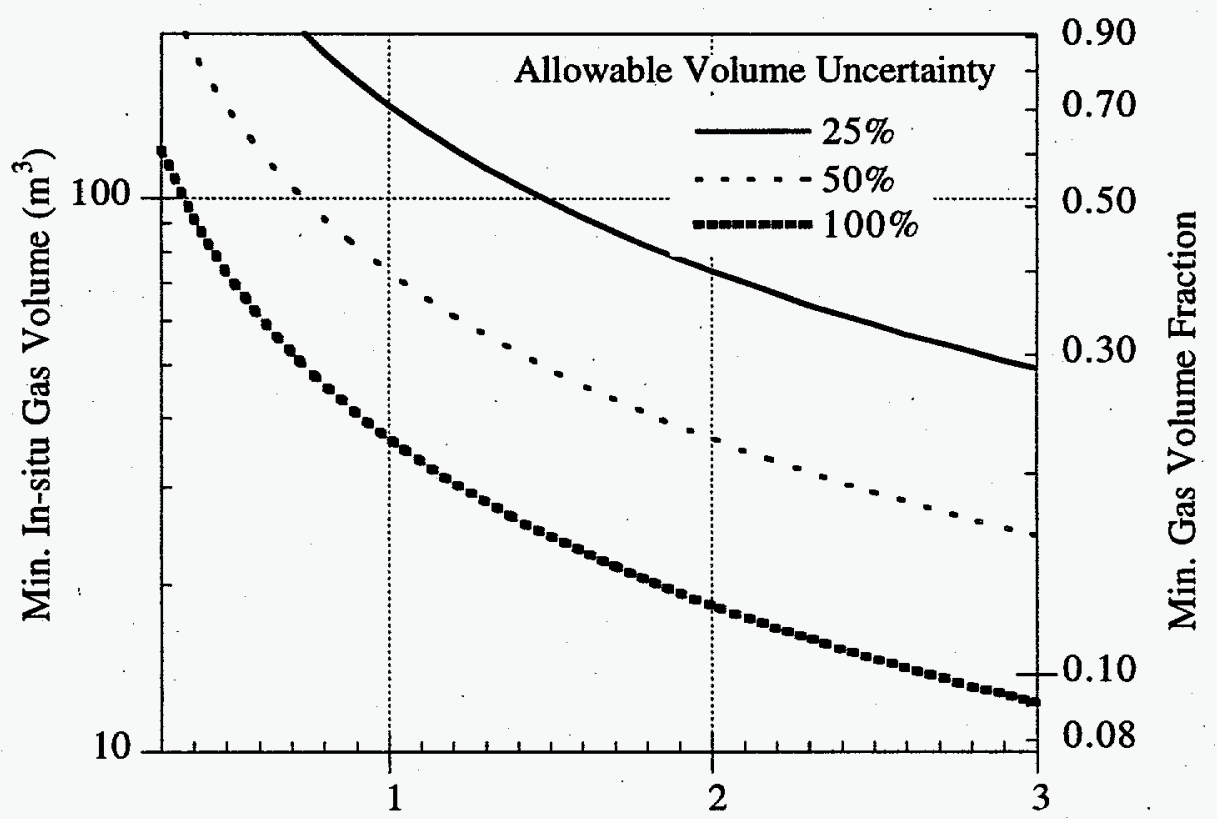

Barometric Pressure Change (kPa)

Figure 2.2. Minimum Detectable Void Fraction, AY-102 Before Transfer 
The figures show that, under nominal barometric pressure swings in the range of $1 \mathrm{kPa}$, the analog Enraf level measurement allows detection of void fractions around 0.02 in C-106 and 0.10 in $\mathrm{AY}-102$. Higher pressure swings, on the order of $2 \mathrm{kPa}$, are required to make a reasonably accurate quantitative estimate of the gas volume. However, such quantification is possible in AY-102 only if the void fraction exceeds about $20 \%$, which is very doubtful.

The BPE model overpredicts the gas volume when the vapor pressure is high. The partial pressure of water vapor is a function only of the local temperature on the time scale of a barometric pressure swing. Since its partial pressure is constant, the volume fraction of water vapor grows as total pressure decreases and vice versa, which amplifies the effect of expansion and compression of the noncondensable gas. Thus there is actually less gas present than the measured $\mathrm{dL} / \mathrm{dP}$ correlation would indicate.

The effect of water vapor can be quantified with the aid of Dalton's and Amagat's laws that relate the mole fractions of the vapor and "non-condensable" gas to the partial pressure and partial volumes as follows:

$$
\frac{n_{i}}{n_{G}}=\frac{p_{i}}{p_{G}}=\frac{V_{i}}{V_{G}}
$$

where $\mathrm{n}$ is the number of moles of gas, $\mathrm{p}$ is the average pressure felt by the gas the $\mathrm{V}$ is the gas volume. The subscript i refers to either the vapor or noncondensable component and the subscript $\mathrm{G}$ refers to the gas mixture. The partial pressure, $p_{i}$ is the pressure that would be exerted by $n_{i}$ moles of gas $i$ contained in the total volume, $V_{G}$. The partial volume, $V_{i}$ is the volume that $n_{i}$ moles of gas $\mathrm{i}$ would occupy under the total pressure, $\mathrm{p}_{\mathrm{G}}$.

Considering only the vapor (subscipt V) and noncondensable (subscript $N$ ) components in Eq. (2.8), the total gas volume can be related to the noncondensable gas partial volume by

$$
\mathrm{V}_{\mathrm{G}}=\left(1+\frac{\mathrm{p}_{\mathrm{V}}}{\mathrm{p}_{\mathrm{N}}}\right) \mathrm{V}_{\mathrm{N}}
$$

The change in waste level with barometric pressure is assumed due solely to compression and expansion of the gas (both vapor and noncondensable). This can be expressed with the aid of Eq. (2.9) by

$$
A \frac{d L_{w}}{d p_{0}}=\frac{d V_{G}}{d p_{0}}=\frac{d}{d p_{N}}\left[\left(1+\frac{p_{V}}{p_{N}}\right) V_{N}\right] \frac{d p_{N}}{d p_{0}}
$$

Taking the derivative, reçognizing that $d p_{N}=d p_{0}$ since $p_{v}$ is a function only of temperature, and assuming isothermal pressure changes such that $\mathrm{pV}_{\mathrm{N}}=\mathrm{n}_{\mathrm{N}} \mathrm{RT}=$ constant, Eq. (2.10) becomes

$$
\mathrm{A} \frac{\mathrm{dL}_{\mathrm{w}}}{\mathrm{dp}_{0}}=-\left(1+\frac{\mathrm{p}_{\mathrm{V}}}{\mathrm{p}_{\mathrm{N}}}\right) \frac{\mathrm{V}_{\mathrm{N}}}{\mathrm{p}_{\mathrm{G}}}-\frac{\mathrm{p}_{\mathrm{V}}}{\mathrm{p}_{\mathrm{N}}^{2}} \mathrm{~V}_{\mathrm{N}}
$$

Converting $V_{N}$ to $V_{G}$ via Eq. (2.9), using $p_{G}=p_{N}+p_{v}$, and rearranging Eq. (2.11) yields 


$$
V_{G}=-A p_{G}\left(1-\frac{p_{V}}{p_{G}}\right) \frac{d L_{w}}{d p_{0}}
$$

Thus, if the water vapor pressure in the bubbles is $10 \%$ of the total pressure, the total gas volume is $90 \%$ of the value indicated by the unmodified BPE model, Eq. (2.1b). The void fraction including the vapor is computed with the analog to Eq. (2.12a) as

$$
\alpha=-\frac{p_{G}}{L_{G}}\left(1-\frac{p_{V}}{p_{G}}\right) \frac{d_{w}}{d p_{0}}
$$

The noncondensible portion of the total gas volume can be found by substituting Eq. (2.9) for $V_{G}$ in Eq. (2.12a) as follows:

$$
\mathrm{V}_{\mathrm{N}}=-\mathrm{Ap}_{\mathrm{G}}\left(1-\frac{\mathrm{p}_{\mathrm{V}}}{\mathrm{p}_{\mathrm{G}}}\right)^{2} \frac{\mathrm{dL}_{\mathrm{w}}}{\mathrm{dp}_{0}}
$$

The water vapor volume fraction in $\mathrm{C}-106$ is about $20 \%$ at the maximum waste temperature of $63^{\circ} \mathrm{C}\left(145^{\circ} \mathrm{F}\right)$ currently indicated by thermocouple \#1 in riser 8, as shown in Figure 2.3. At this temperature, the actual void fraction via Eq. (2.12b) would be $80 \%$ of that calculated from Eq. (2.1a). If the average gas temperature is $53^{\circ} \mathrm{C}\left(128^{\circ} \mathrm{F}\right)$ as represented by thermocouple $\# 2$ is riser 8 and thermocouple \#1 in riser 14, the water vapor fraction is $13 \%$ and the actual void fraction would be about $87 \%$ of the value from Eq. (2.1a). Eq. (2.13) shows that $75 \%$ of the gas volume computed from Eq. (2.1b) is noncondensible. However, use of the unmodified BPE model without considering water vapor is conservative.

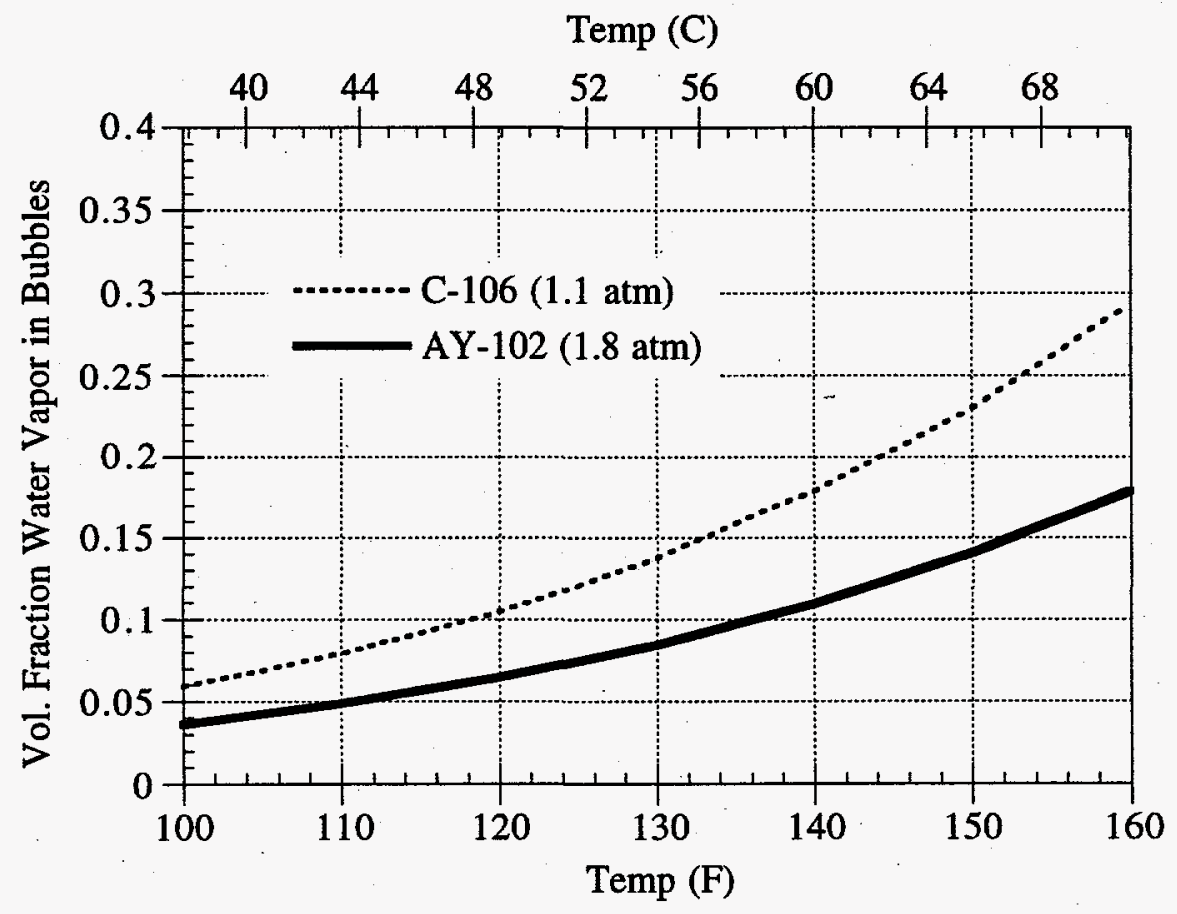

Figure 2.3. Fraction of Water Vapor in Gas Bubbles 


\subsection{Statistical Methods to Obtain $\mathrm{dL} / \mathrm{dP}$}

The tank waste level response to atmospheric pressure changes, dL/dP, for Tank C-106 was estimated using the "Parallelogram Model." A detailed derivation of the model can be found in Whitney et al. (1997).

The model assumes that gas is present in the waste in the form of small, round bubbles. When the pressure far from a bubble is increased or decreased, stresses are transmitted within the elastic waste that deform the bubble. If the surrounding pressure field is hydrostatic, the deformations are radial. When pressure changes are large enough, circumferential stress at the bubble wall can become large enough to fail the waste material. Failure is assumed to happen when induced stresses exceed the yield strength of the waste, $\tau_{y}$.

The bubble geometry, together with the assumed waste material properties, implies that yielding of the waste occurs after a total external pressure change of $2 \tau_{y}$. Once yielding has occurred, it is assumed that plastic flow takes place. The model simply assumes free flow of the waste after yielding, as long as the pressure gradient does not reverse. Once the pressure gradient reverses, the model assumes that the waste "sets up" again, and flow does not occur until the net pressure change since the reversal again exceeds $2 \tau_{y}$. When a barometric pressure swing (i.e., passage of a low pressure system or strong cold front) exceeds twice the yield stress, a plot of waste level versus pressure produces a parallelogram over the cycle, as sketched in Figure 2.4; hence the name for the model.

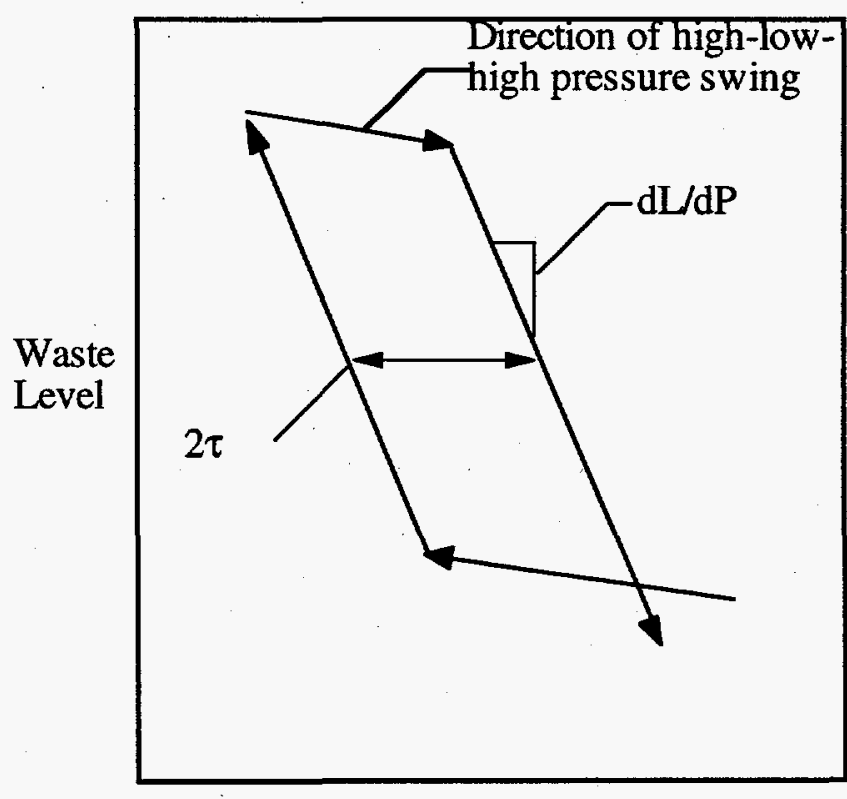

Barometric Pressure

Figure 2.4. Waste Level Versus Pressure Parallelogram 
Whitney et al. (1997) show that the measured waste level in many waste tanks follows the parallelogram model closely. The correlation of level and pressure, $\mathrm{dL} / \mathrm{dP}$, is estimated as the changing rate of the waste level in conjunction with atmospheric pressure changes over the periods of plastic flow represented by the "steep" sides of the parallelogram, not in regions of elastic deformation represented by the upper and lower bases of the parallelogram.

For a given value of $2 \tau_{y}$, the model extracts all (level and pressure) pairs that correspond to the plastic flow status of the waste for each specific atmospheric pressure cycle. Those pairs are then used to estimate $\mathrm{dL} / \mathrm{dP}$ value for the pressure swing. Two linear regression fitting methods are used to obtain the correlation of waste level on pressure, dL/dP: ordinary least squares fit and "robust" least squares fit. The robust linear fit is designed to accommodate possible deviation from linearity in the relation between level and pressure caused by the potential time lag effects between pressure and level changes and the potential for mis-specified $2 \tau_{\mathrm{y}}$ values (Whitney et al. 1997).

\subsection{Reduction of Raw Level Data}

The complicated process by which waste level data are determined appropriate for developing the $\mathrm{dL} / \mathrm{dP}$ correlation must overcome three main difficulties. A huge amount of raw level data must be reduced, the precision required to sense the relatively small volume of gas pushes the limits of the instrumentation, and the effects of nonuniform evaporation and periodic water addition must be removed. This section discusses the methods applied to deal with the first two problems. Removing evaporation effects by detrending the data is discussed in Section 2.4.

The level measurements are recorded directly from an Enraf buoyancy gauge in riser 7. Both digital and analog output are sent to separate files in the RAW-DATA table in the Surveillance Analysis Computer System (SACS) database, which is part of the Tank Monitoring and Control System (TMACS). The precision of the digital data has been estimated as \pm 0.004 inches, though it is recorded only to the nearest 0.01 inches, and that of the analog data is \pm 0.01 inches. The recording logic uses a "delta band" of 0.01 inches with a polling frequency of one minute. ${ }^{(a)}$

The high polling frequency produces an extremely high data density and, because the delta band is very close to the precision of the device, many of the data are noise that appears as an oscillation between values separated by 0.01 inches. At the same time, evaporation causes the level to decrease continually. The combination of effects causes the raw level data to appear as a series of "stair steps." This is shown in Figures 2.5 and 2.6, which plot raw analog and digital data, respectively, for a two-day period. A three-hour close-up view of the digital data is also shown in Figure 2.7.

The horizontal segments, which are more pervasive in the analog data, have been viewed as evidence that the level gauge was "sticking," which has occasioned the replacement of several components. However, as implied above, this behavior is now attributed to using a delta band of nearly the same width as the precision of the signal.

(a) This means that the instrument is read at the polling frequency, once every minute, and a new data point is recorded if the new reading differs from the last one by more than the delta band, 0.01 inches. 


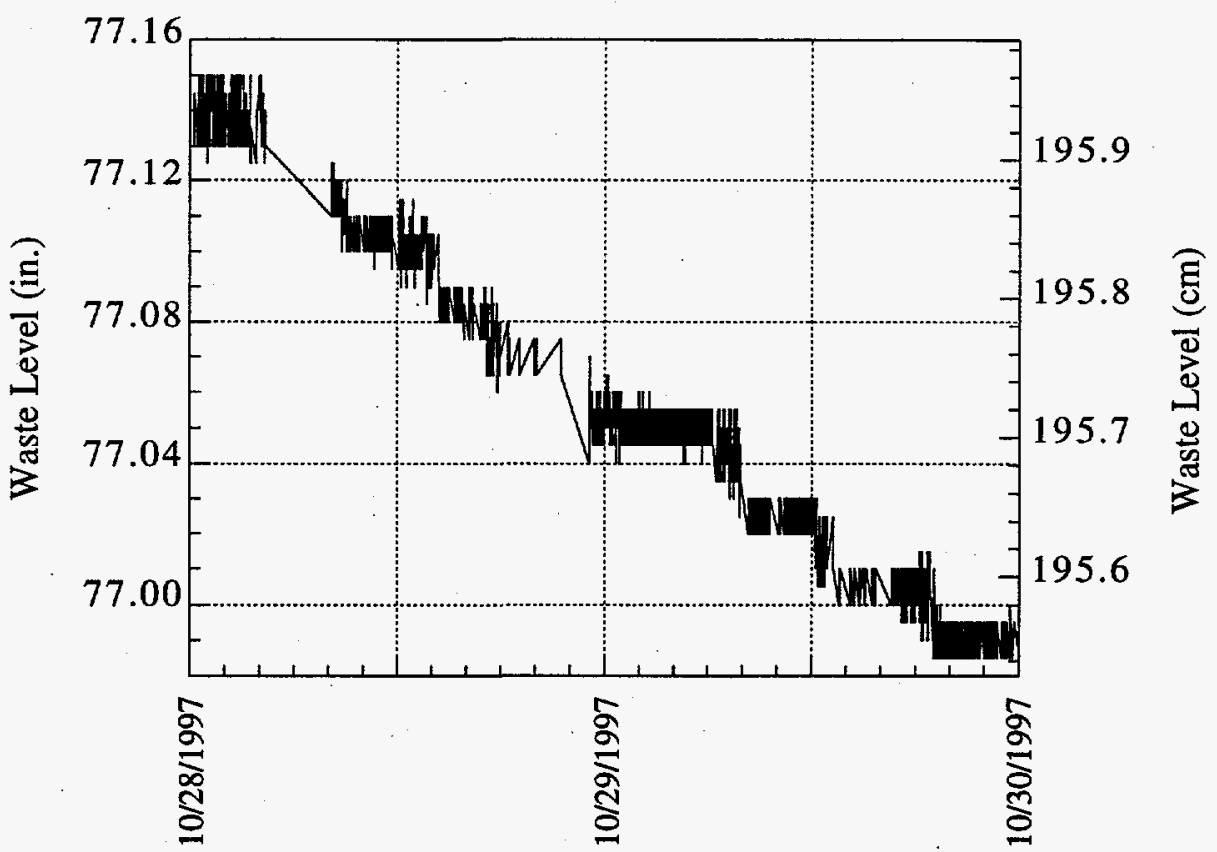

Figure 2.5. Raw Analog Level Data from C-106-Stairstep View

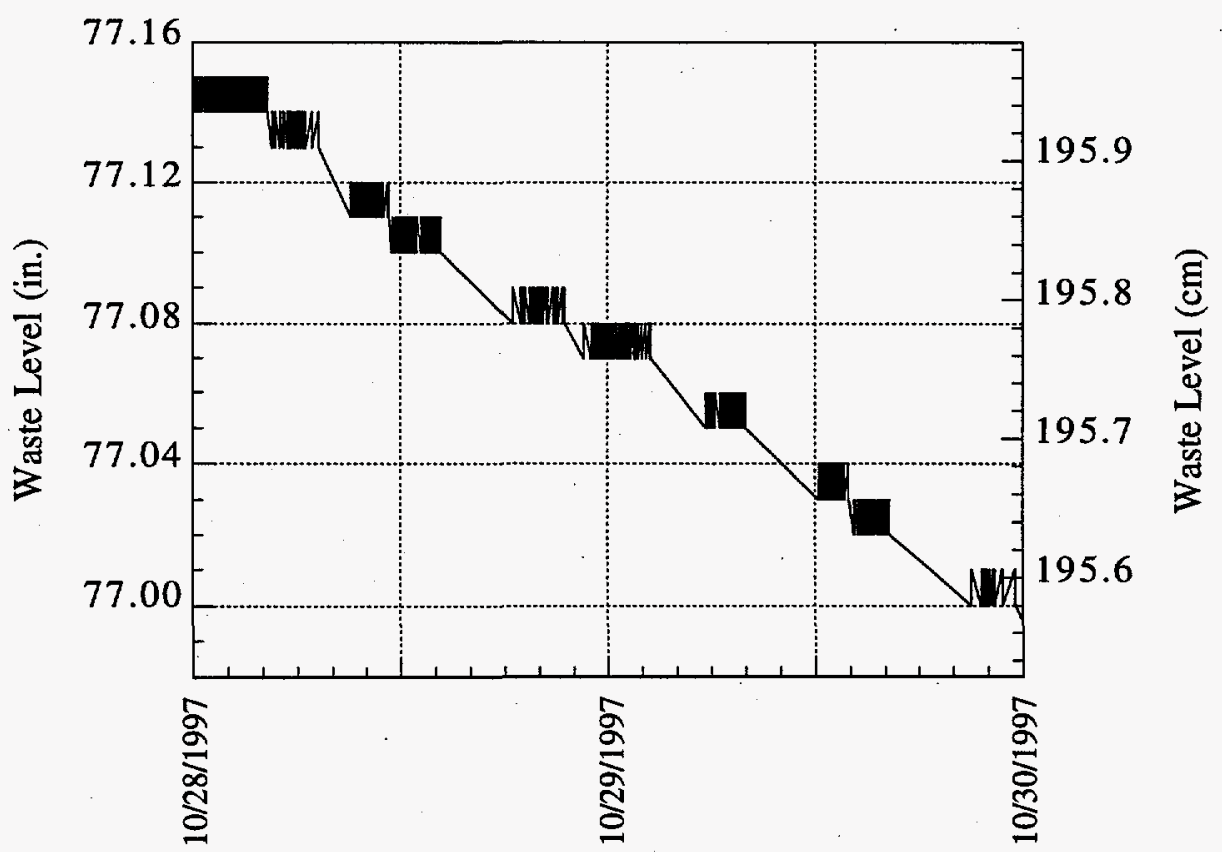

Figure 2.6. Raw Digital Level Data from C-106-Stairstep View 


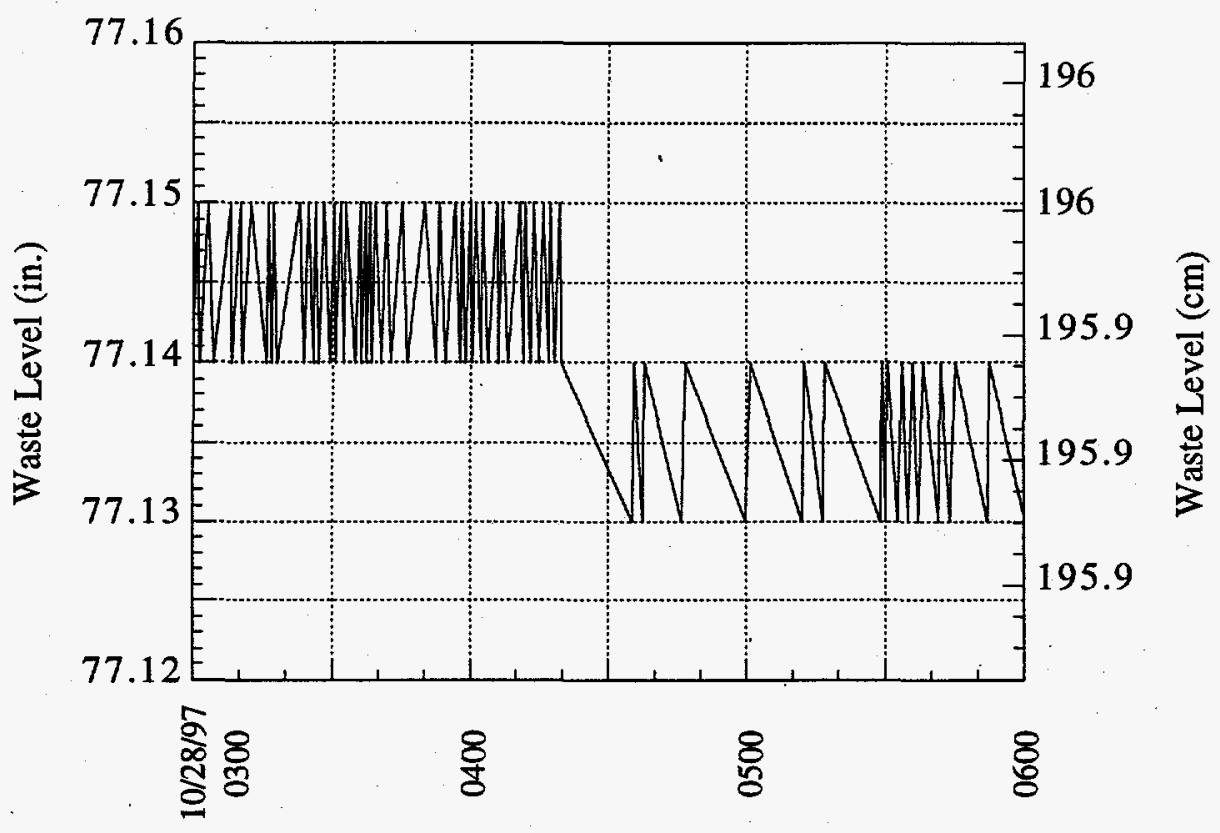

Figure 2.7. Close-up of C-106 Raw Digital Level Data

The noise in the data must be removed to produce a useful dL/dP correlation. First, we choose to deal only with the digital data because it is much less noisy to begin with. The stairstep pattern is the primary (almost the only) feature in the raw digital data. We assume that each "step" represents a single data point at its centroid. The center point is computed as the average of the time and level coordinates of the upper right and lower left corner points of the step. The upper and lower corners are found by a combination of numerical search logic and manual interpretation. ${ }^{\left({ }^{2}\right)}$. The center and the two corners define each stairstep with three reduced data points, as shown in Figure 2.8. The corners also bound the raw data and define the total uncertainty in the level measurement. The data in Figure 2.8 lie within a fairly uniform band 0.02 inches wide, about twice the width of the delta band.

\subsection{Detrending to Remove the Effect of Evaporation}

The reduced data (center points) for the entire time period are plotted in Figure 2.9. Water was added three times, and the variable slope between additions is clearly visible. The evaporation rate becomes lower immediately after relatively cool water is added. This is evident in the early portions of periods labeled B, C, and D. Later in the period, as in the portion of period A shown, prior to the first water addition, the evaporation rate becomes nearly constant. Still later in the period, for example, the latter part of period $\mathrm{C}$ immediately before the third water addition, the evaporation rate decreases slightly. Two weeks of data are missing-January 7 to 22 .

(a) We could not construct a logic structure that could reconcile all the variations of level behavior automatically. Fortunately, it is quite easy for the human eye to detect the "corners," though processing approximately 30,000 data points this way takes several days. 


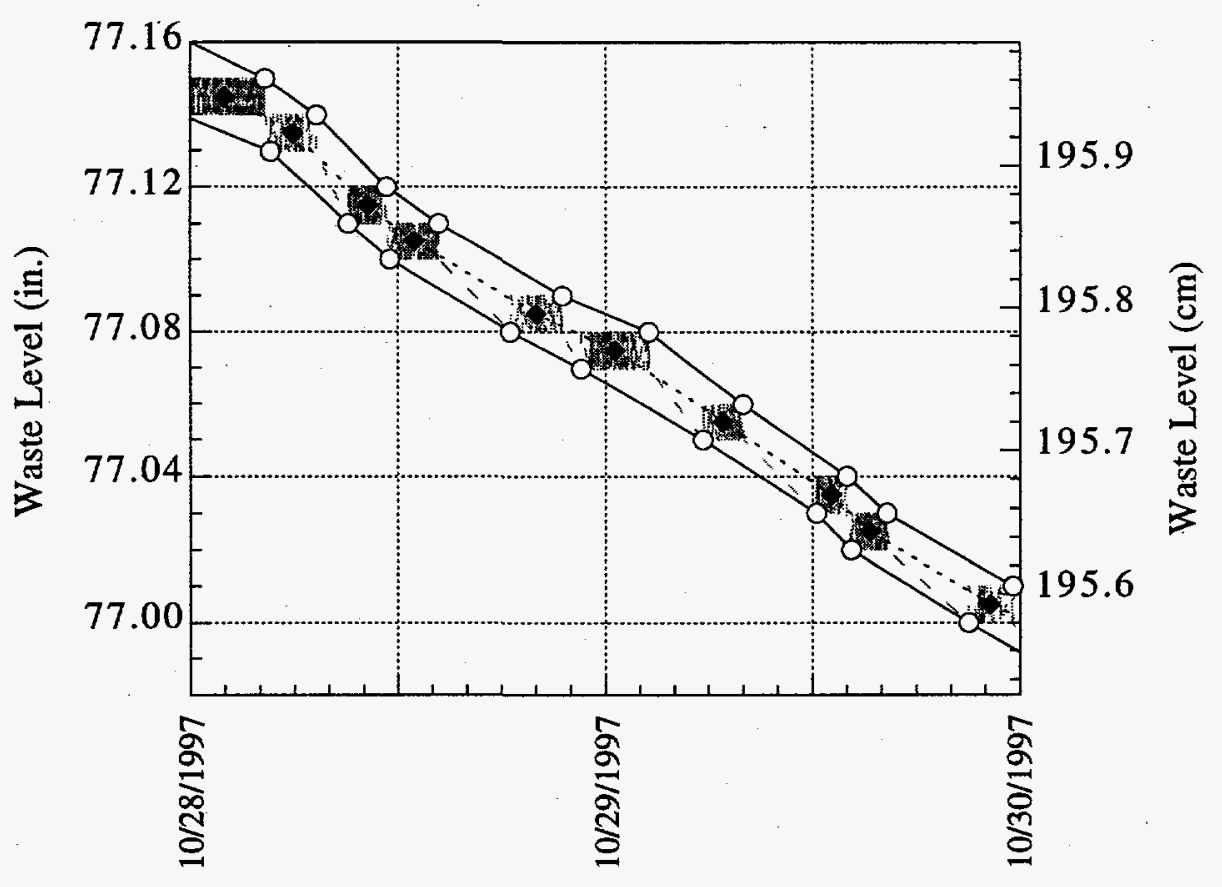

Figure 2.8. Reduced C-106 Digital Level Data—Stairstep View

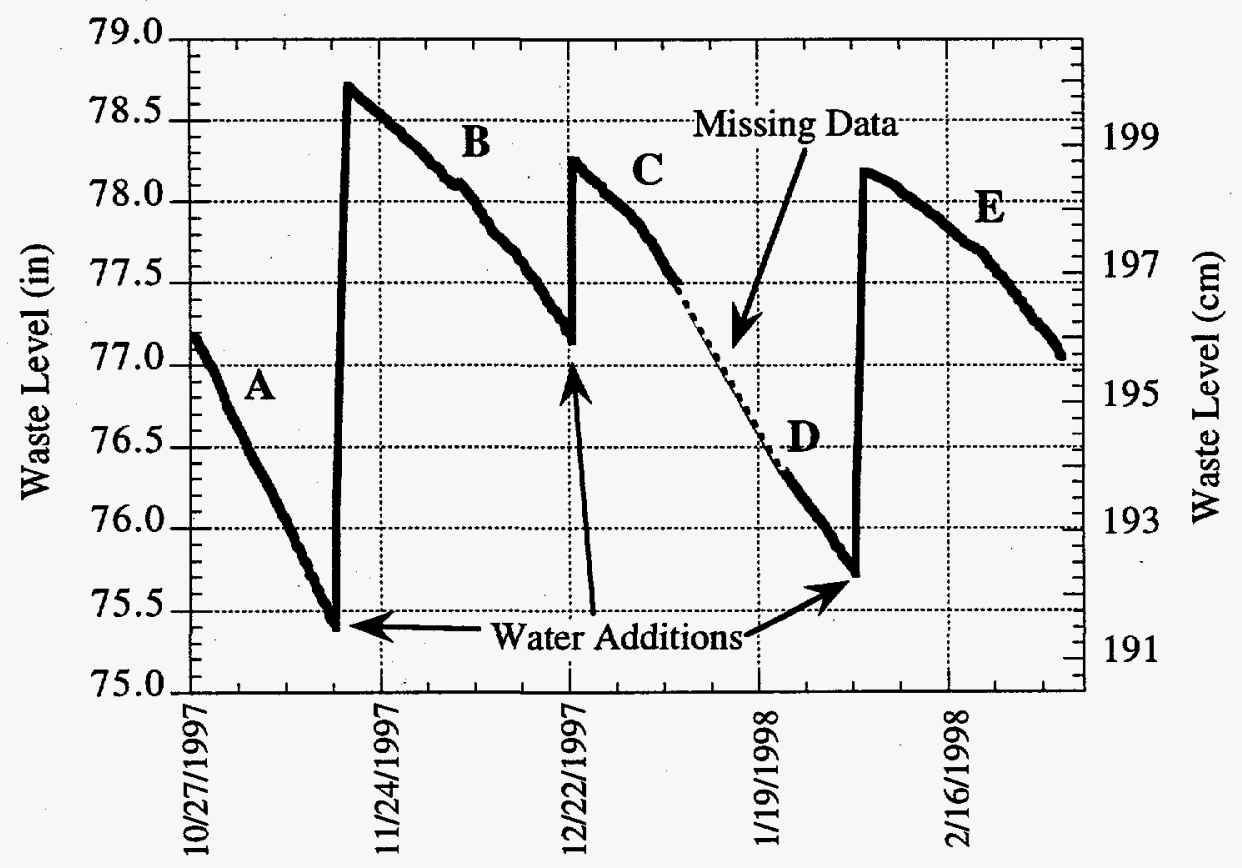

Figure 2.9. Reduced Digital Level Data for C-106, 10/28/97-3/4/98 
The detrending process removes the long-term trends so that only the short-term effects of barometric pressure variations are left. In this case it is clear that a simple linear as is typically used (Whitney et al. 1996) is not sufficient. Instead, quadratic functions were used as expressed by

$$
\mathrm{L}_{d t}(\mathrm{t})=\mathrm{L}(\mathrm{t})-\left[\mathrm{C}_{0}-\mathrm{C}_{1}\left(\mathrm{t}-\mathrm{t}_{0}\right)-\mathrm{C}_{2}\left(\mathrm{t}-\mathrm{t}_{0}\right)^{2}\right]
$$

where $L_{d t}(t)$ is the detrended level at time $t, L(t)$ is the measured level at time $t, t_{0}$ is time at the beginning of a detrending period, and $\mathrm{C}_{0}, \mathrm{C}_{1}$, and $\mathrm{C}_{2}$ are constants.

The coefficients are derived for each detrending period noted in Figure 2.9 by minimizing the standard deviation of Eq. (2.13) over all reduced data in the period. The resulting detrended levels for the same two days shown in Figures 2.6 and 2.8 are plotted in Figure 2.10. Figure 2.11 shows the detrended data for the entire period.

The coefficients, maximum and minimum values of $\mathrm{L}_{\mathrm{dt}}$, and the final standard deviation from zero for each of the four detrending periods are listed in Table 2.1. Note that the standard deviation is within the error band of the reduced data. The maxima and minima, which represent the effects of barometric pressure variation, are only 2-3 times the standard deviation, which implies that there will be a relatively high uncertainty in the $\mathrm{dL} / \mathrm{dP}$ correlation derived from these data.

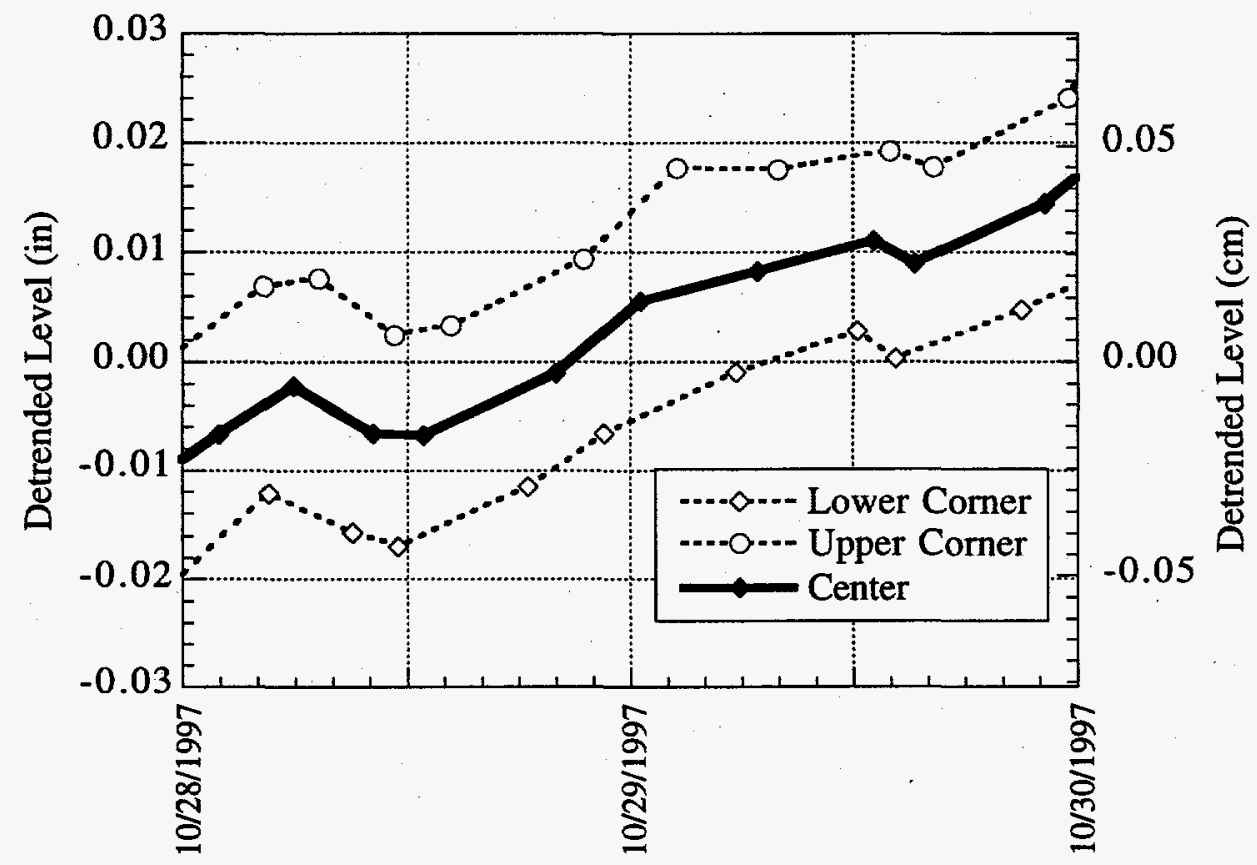

Figure 2.10. Segment of Detrended Level Data for C-106 


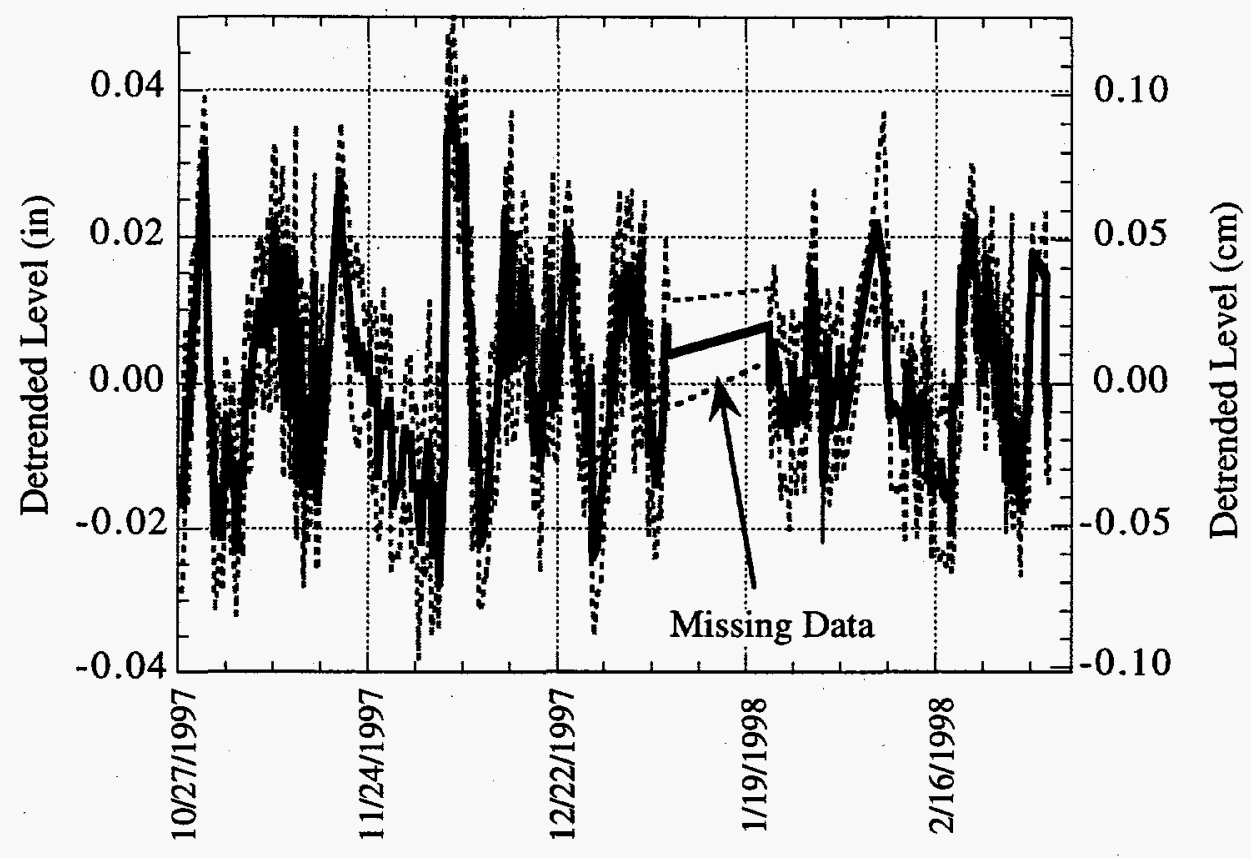

Figure 2.11. Detrended Level Data for C-106, 10/27/97-3/4/98

Table 2.1. Detrending Parameters

\begin{tabular}{|l|c|c|c|c|c||}
\hline & A & B & C & D & E \\
\hline C0 & 77.182 & 78.677 & 78.197 & 76.357 & 78.106 \\
\hline C1 & $8.731 \mathrm{E}-2$ & $2.854 \mathrm{E}-2$ & $2.465 \mathrm{E}-2$ & $5.595 \mathrm{E}-2$ & $1.948 \mathrm{E}-2$ \\
\hline C2 & $-5.124 \mathrm{E}-5$ & $5.038 \mathrm{E}-4$ & $1.622 \mathrm{E}-3$ & $2.360 \mathrm{E}-4$ & $7.951 \mathrm{E}-4$ \\
\hline Maximum & 0.0316 & 0.0391 & 0.0209 & 0.0152 & 0.0220 \\
\hline Minimum & -0.0231 & -0.0281 & -0.0241 & -0.0132 & -0.0203 \\
\hline Std. Deviation & 0.0122 & 0.0151 & 0.0106 & 0.0056 & 0.0105 \\
\hline \hline
\end{tabular}




\subsection{Gas Volume Estimate for C-106}

As described in Section 2, it is absolutely necessary to choose well-defined and large barometric pressure swings to obtain a good estimate of the pressure/level correlation. Five such periods were found between October 27, 1997, and March 4, 1998, for which there was a good correlation. In this section, the mean and bounding values are developed from the five resulting $\mathrm{dL} / \mathrm{dP}$ values, and the corresponding mean and bounding void fraction and gas volume are computed.

\section{$3.1 \mathrm{dL} / \mathrm{dP}$ Correlation}

The detrended level measurements described in Section 2.4 and shown in Figure 2.9 were used for $\mathrm{dL} / \mathrm{dP}$ estimation. A few outlying detrended data points were further eliminated that were measured shortly after water additions. Hourly atmospheric pressure data were obtained from the Hanford Meteorological Station (HMS). The pressure at each level measurement time was determined through a linear interpolation of the hourly pressure data. The pressure data are shown in Figure 3.1.

\subsubsection{Selection of Barometric Pressure Intervals}

To apply the "Parallelogram Model," values must be selected for the time lag and the $2 \tau_{\mathrm{y}}$ parameter. Two values of $2 \tau_{\mathrm{y}}$ were applied for the estimation: 0.2 and $0.4 \mathrm{in}$. $\mathrm{Hg}$, corresponding to a yield stress of 340 and $680 \mathrm{~Pa}$, respectively. Though the yield stress has not been measured in $\mathrm{C}-106$, the former value is most consistent with the available evidence. The time lag in this estimation was defined as zero.

With those parameter values, more than 20 free-flow status intervals were identified over the time period from October 27,1997 , to March 4, 1998. Only five of those intervals (with $2 \tau_{\mathrm{y}}=$ 0.2 in. $\mathrm{Hg}$ ), however, showed relatively large pressure changes and contained adequate numbers of level measurements. These are shown in the shaded areas of Figure 3.1 and listed in Table 3.1. Individual pressure swings are plotted in Figures 3.2 through 3.5.

Table 3.1. Selected Barometric Pressure Intervals

\begin{tabular}{|c|c|c|}
\hline & $\begin{array}{c}\text { Pressure Change } \\
\text { (in. Hg) }\end{array}$ & Number of Points \\
\hline $10 / 31 / 97$ & 0.584 & 13 \\
$12 / 09 / 97$ & 0.975 & 13 \\
$12 / 18 / 97$ & 0.480 & 8 \\
$02 / 22 / 98$ & 0.371 & 10 \\
$02 / 27 / 98$ & 0.284 & 13 \\
\hline
\end{tabular}




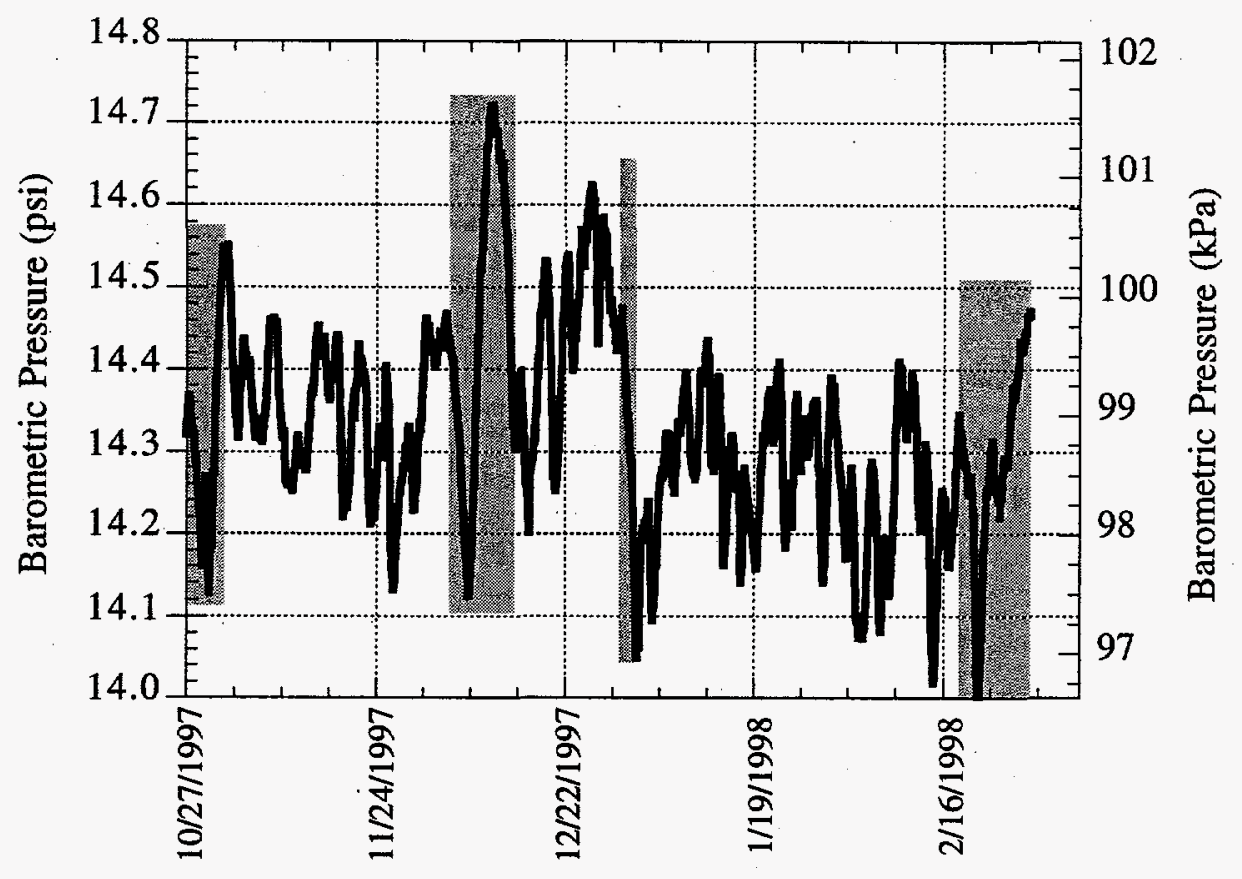

Figure 3.1. Barometric Pressure, 10/27/98-2/28/98

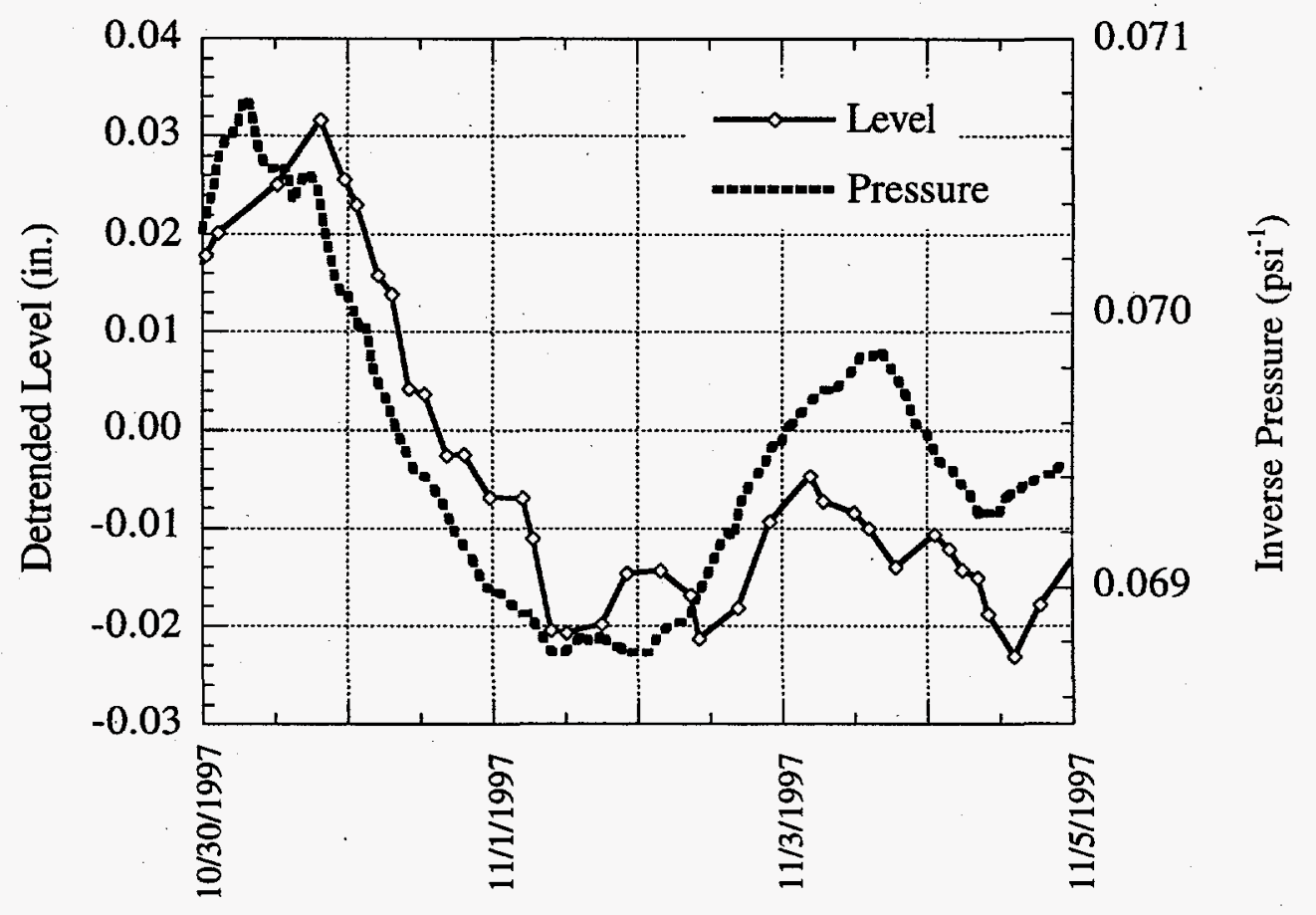

Figure 3.2. Inverse Pressure/Level Correlation, 10/30/97-11/5/97 


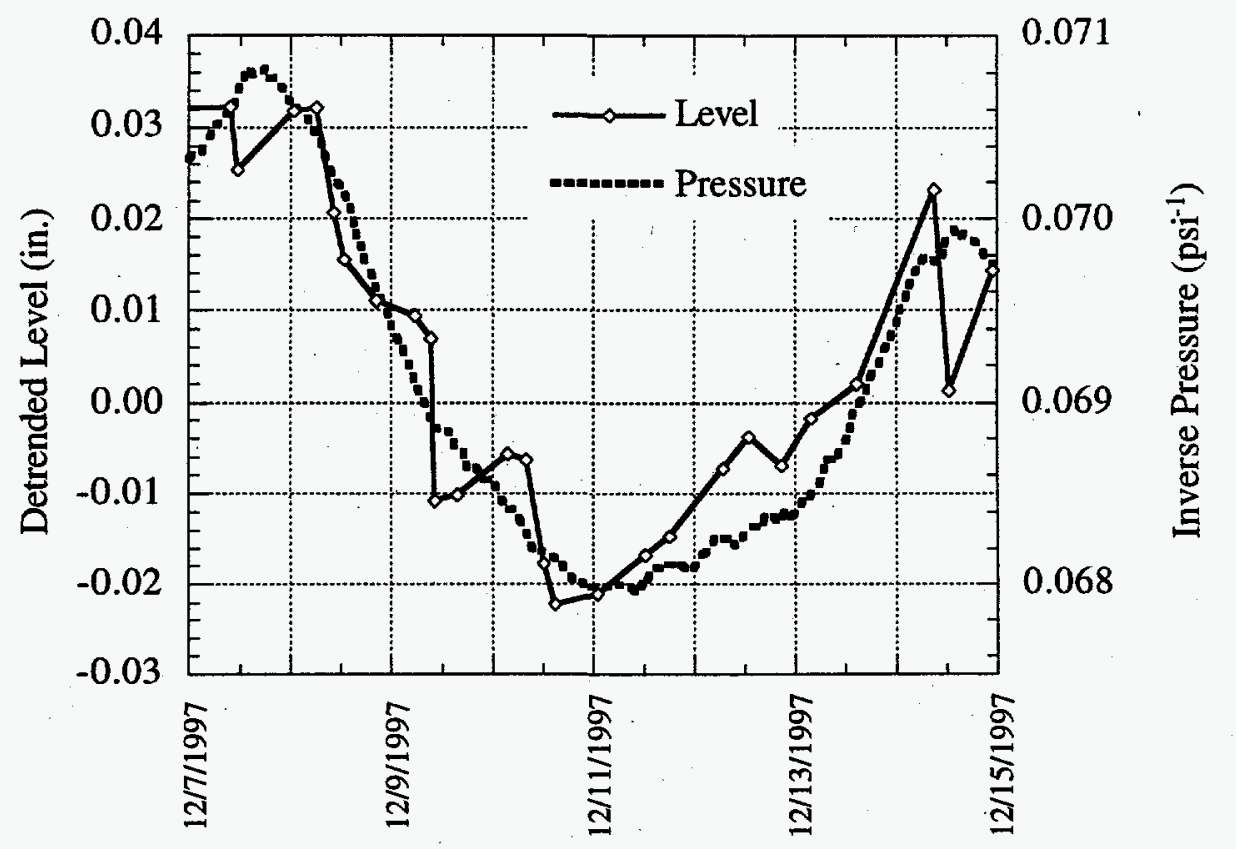

Figure 3.3. Inverse Pressure/Level Correlation, 12/7/97-12/15/97

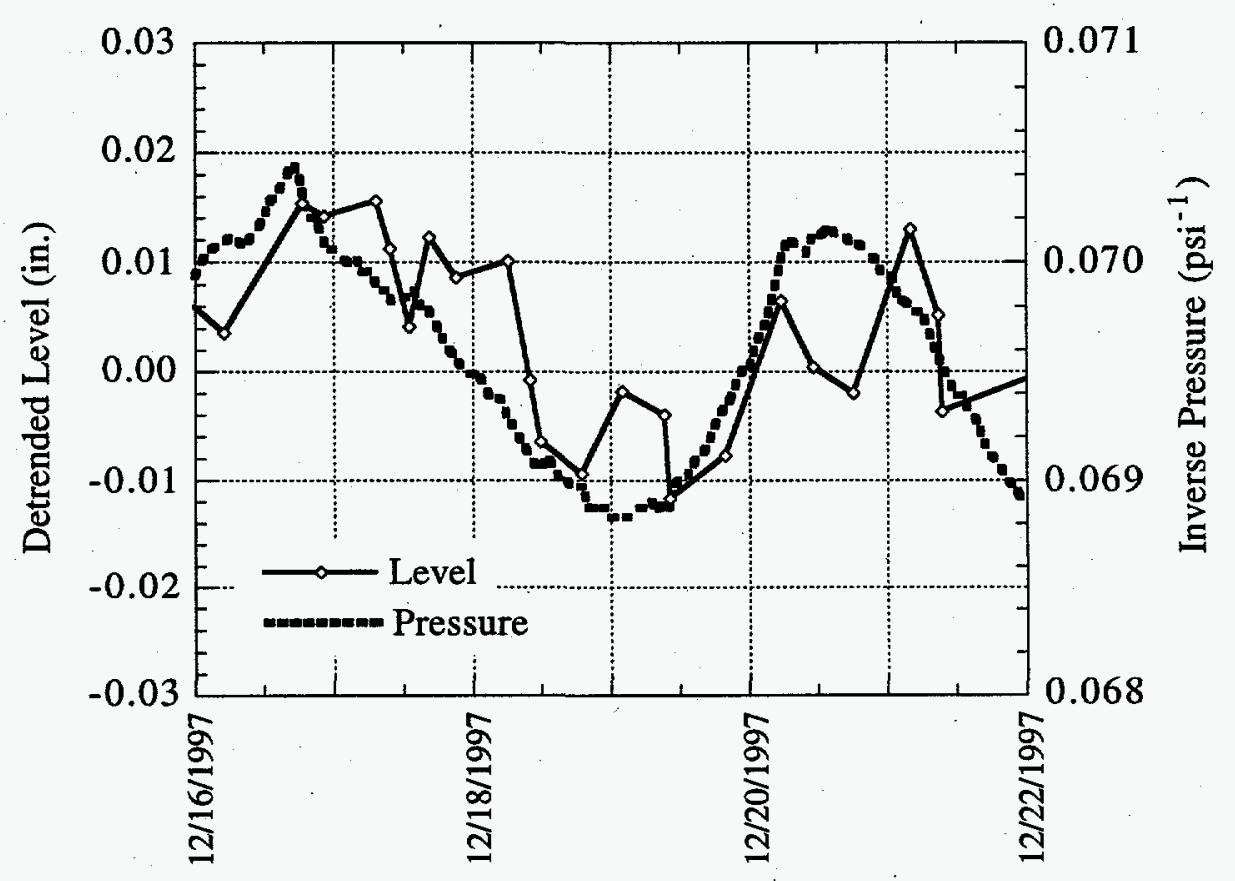

Figure 3.4. Inverse Pressure/Level Correlation, 12/16/97-12/22/98 


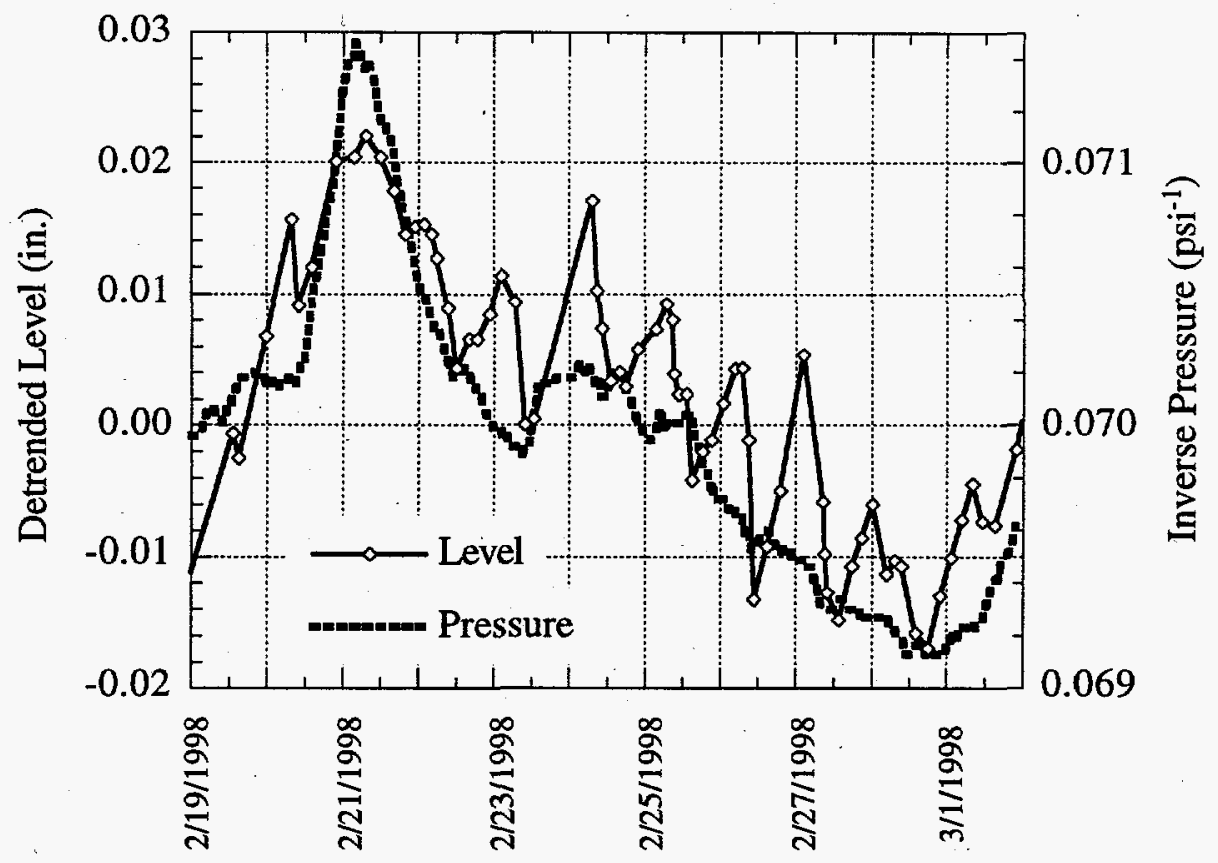

Figure 3.5. Inverse Pressure/Level Correlation, 2/19/97-3/2/98

\subsubsection{Estimates of $\mathrm{dL} / \mathrm{dP}$}

The dL/dP estimates from the five intervals are listed in Table 3.2 using the two linear fit methods. The numbers in the column "sd" are the estimated standard deviations associated with individual $\mathrm{dL} / \mathrm{dP}$ estimates. The dates in the "Interval" column indicate the middle day of the pressure cycles.

Table 3.2. Estimates of $\mathrm{dL} / \mathrm{dP}$ (in./in. $\mathrm{Hg}$ )

\begin{tabular}{||c|c|c|c|c|c||}
\hline & & \multicolumn{2}{|c|}{ Least Square Fit } & \multicolumn{2}{c||}{ Robust Fit } \\
\cline { 3 - 6 } Interval & $\begin{array}{c}2 \tau_{\mathrm{y}} \\
\text { (in. Hg) }\end{array}$ & $\begin{array}{c}\mathrm{dL} / \mathrm{dP} \\
\text { (in./in. Hg) }\end{array}$ & sd & $\begin{array}{c}\mathrm{dL} / \mathrm{dP} \\
\text { (in./in. Hg) }\end{array}$ & sd \\
\hline $10 / 31 / 97$ & 0.2 & -0.074 & 0.0041 & -0.073 & 0.0034 \\
$12 / 09 / 97$ & 0.2 & -0.041 & 0.0048 & -0.042 & 0.0045 \\
$12 / 18 / 97$ & 0.2 & -0.046 & 0.0094 & -0.054 & 0.0089 \\
$02 / 22 / 98$ & 0.2 & -0.023 & 0.0087 & -0.023 & 0.0084 \\
$02 / 27 / 98$ & 0.2 & -0.058 & 0.0092 & -0.056 & 0.0081 \\
\hline Overall & 0.2 & -0.048 & 0.0191 & -0.050 & 0.0185 \\
\hline $10 / 31 / 97$ & 0.4 & -0.072 & 0.0075 & -0.073 & 0.0072 \\
$12 / 09 / 97$ & 0.4 & -0.044 & 0.0078 & -0.045 & 0.0081 \\
$02 / 27 / 98$ & 0.4 & -0.058 & 0.0092 & -0.056 & 0.0081 \\
\hline
\end{tabular}


For $2 \tau_{\mathrm{y}}=0.4 \mathrm{in}-\mathrm{Hg}, \mathrm{dL} / \mathrm{dP}$ estimates, shown in the row "Overall," were reported from only three intervals. The estimates from the other two intervals were omitted because the number of level measurements corresponding to the "free flow" status in those intervals became small at the higher value. The estimates based on $2 \tau_{\mathrm{y}}=0.4 \mathrm{in}$. $\mathrm{Hg}$ are reported here for a comparison purpose. The impact of $2 \tau_{\mathrm{y}}$ value is not significant in this study since both the least squares fit and the robust fit give every similar estimates for those intervals and both $2 \tau_{\mathrm{y}}$ values.

A mean estimate of $\mathrm{dL} / \mathrm{dP}$ for each linear fit method is obtained by taking sample mean of the five estimates with $2 \tau_{\mathrm{y}}=0.2 \mathrm{in}-\mathrm{Hg}$. Similarly, the associated standard deviation is estimated by the sample standard deviation of the five values. Those mean $\mathrm{dL} / \mathrm{dP}$ estimates may not be very reliable since they are based on only five time intervals. No mean $\mathrm{dL} / \mathrm{dP}$ were calculated using the estimates with $2 \tau_{y}=0.4 \mathrm{in}-\mathrm{Hg}$ because the number of available intervals is too small.

\subsection{Void Fraction and Retained Gas Volume}

The best-estimate and standard deviation of the robust fit dL/dP correlation from Table 3.2 are $-0.05 \pm 0.0185 \mathrm{in} . / \mathrm{in}-\mathrm{Hg}$. Converting the units to $\mathrm{cm} / \mathrm{kPa}$ and taking three standard deviations as the $99 \%$ confidence limit yields -0.037 and $-0.079 \mathrm{~cm} / \mathrm{kPa}$ as the best-estimate and conservative estimate, respectively. We now apply Eq. (2.2), (2.1) and (2.3) to calculate the pressure, void fraction, in situ gas volume, and standard gas volume, respectively. The calculations and input data are listed in Table 3.1. Note that the 30-cm "hardpan" layer in the concave bottom portion of the tank is not included in the gas bearing solids layer.

\subsubsection{Void Fraction}

The maximum waste level from Enraf measurements is $198 \mathrm{~cm}(78 \mathrm{in}$.). There is $176.5 \mathrm{~cm}$ (69.5 in.) of gas-bearing nonconvective solids (all measurements excluding the dish bottom [Bailey 1998]). With a liquid density of $1170 \mathrm{~kg} / \mathrm{m}^{3}$ and a nonconvective layer density of $1550 \mathrm{~kg} / \mathrm{m}^{3}$ (Carothers et al. 1998), Eq. (2.2) gives an average gas pressure of $117.5 \mathrm{kPa}$ $(1.16 \mathrm{~atm})$. With this pressure and a depth of $176.5 \mathrm{~cm}(69.5 \mathrm{in}$.$) , Eq. (2.1a) gives the best$ estimate and conservative void fractions as 0.025 and 0.053 , respectively.

\subsubsection{Gas Volume}

Multiplying the void fractions by the total gas-bearing sludge volume, the corresponding best-estimate and conservative in situ gas volumes are $18 \mathrm{~m}^{3}\left(640 \mathrm{ft}^{3}\right)$ and $38 \mathrm{~m}^{3}\left(1340 \mathrm{ft}^{3}\right)$, respectively, using Eq. (2.1b). Assuming an average temperature of $338 \mathrm{~K}(150 \mathrm{~F})$ based on the lowest thermocouple on the tree in riser 8 , and correcting these volumes to standard conditions (1 atmosphere, 298K) with Eq. (2.3) gives $24 \mathrm{scm}(840 \mathrm{scf})$ and $50 \mathrm{scm}(1770 \mathrm{scf})$, respectively. 
Table 3.3. Summary of Gas Volume Calculations

\begin{tabular}{|c|c|c|}
\hline \multicolumn{3}{|l|}{ Input Values } \\
\hline $\begin{array}{l}\text { Waste Level } \\
\text { Nonconvective layer depth } \\
\text { Supernatant liquid depth } \\
\text { Liquid density } \\
\text { Nonconvective layer density } \\
\text { Average gas temperature } \\
\text { dL/dP (Sec. } 3.1 \text { ) } \\
\text { Pressure (Eq. } 2.2 \text { ) }\end{array}$ & \multicolumn{2}{|c|}{$\begin{array}{c}198 \mathrm{~cm}(78 \mathrm{in} .) \\
176.5 \mathrm{~cm}(69.5 \mathrm{in} .) \\
21.5 \mathrm{~cm}(8.5 \mathrm{in} .) \\
1,170 \mathrm{~kg} / \mathrm{m}^{3} \\
1,550 \mathrm{~kg} / \mathrm{m}^{3} \\
338 \mathrm{~K}\left(150^{\circ} \mathrm{F}\right) \\
-0.037,-0.079(\mathrm{~cm} / \mathrm{kPa}) \\
117.5 \mathrm{kPa}(1.16 \mathrm{~atm})\end{array}$} \\
\hline Computed Values & mean & 99 percentile \\
\hline $\begin{array}{l}\text { Void fraction (Eq. 2.1a) } \\
\text { In situ gas volume (Eq. 2.1b) } \\
\text { Standard gas volume (Eq. 2.3) }\end{array}$ & $\begin{array}{c}0.025,0.053 \\
18 \mathrm{~m}^{3}\left(640 \mathrm{ft}^{3}\right) \\
24 \mathrm{scm}(840 \mathrm{scf})\end{array}$ & $\begin{array}{c}38 \mathrm{~m}^{3}\left(1340 \mathrm{ft}^{3}\right) \\
50 \mathrm{scm}(1770 \mathrm{scf})\end{array}$ \\
\hline
\end{tabular}




\subsection{Conclusions}

The baseline retained gas inventory in C-106 has been estimated by the BPE method, which correlates waste surface level fluctuations to barometric pressure changes. The BPE method is the only practicable method available to quantify the gas inventory in C-106 prior to sluicing. Waste level and barometric pressure data were obtained for the period from October 27, 1997, to March 4, 1998. Five significant barometric pressure swings were identified that correlated well with waste level changes. The level data were detrended to remove the effect of evaporation and periodic makeup water addition and a large fraction of the huge quantity of precise but noisy measurements was eliminated. The resulting reduced data had a total uncertainty band of about $\pm 0.025 \mathrm{~cm}( \pm 0.01 \mathrm{in}$.$) .$

The best-estimate and conservative values of the level/pressure correlation slopes, $\mathrm{dL} / \mathrm{dP}$, determined for the five pressure swings are -0.037 and $-0.079 \mathrm{~cm} / \mathrm{kPa}$, respectively. This gives the best-estimate and conservative void fractions as 0.025 and 0.053 , and corresponding standard retained gas volumes of $24 \mathrm{scm}(840 \mathrm{scf})$ and $50 \mathrm{scm}$ (1770 scf), respectively.

The analyses in the W-320 Flammable Gas topical report (Pasamehmetoglu et al. 1997) assumed a best-estimate void fraction of $\leq 0.07$ with a bounding value of 0.15 . Because the conservative estimate of the void fraction in the current analysis is only 0.053 , which is well below Los Alamos National Laboratory's best estimate, we can conclude that the strategy for controlling flammable gas accumulation and release in Process Control Plan is based on a quite conservative assumption of the retained gas volume. 


\subsection{References}

Bailey JW. 1998. Project W-320 SAR and Process Control Thermal Analyses. HNF-SD-W320ER-004 Rev. 1, Numatec Hanford Company, Richland, Washington.

Carothers KG, SD Estey, NW Kirch, LA Stauffer, and JW Bailey. 1998. Tank 241-C-106 Waste Retrieval Sluicing System Process Control Plan. HNF-SD-WM-PCP-013 Rev. 0, Lockheed Martin Hanford Company, Richland, Washington.

Gauglitz PA, SD Rassat, PR Bredt, JH Konynenbelt, JM Tingey, and DP Mendoza. 1996. Mechanisms of Gas Bubble Retention and Release: Results for Hanford Waste Tanks 241-S-102 and 241-SY-103 and Single-Shell Tank Simulants. PNNL-11298, Pacific Northwest National Laboratory, Richland, Washington.

Jones JM. 1997. Process Test Plan: Tank 241-C-106 296-P-16 Exhauster Outage. HNF-SDWM-PTP.-030 Rev. 0, Lockheed Martin Hanford Company, Richland, Washington.

Meyer PA, ME Brewster, SA Bryan, G Chen, LR Pederson, CW Stewart, and G Terrones. 1997. Gas Retention and Release Behavior in Hanford Double Shell Waste Tanks. PNNL-11536 Rev. 1, Pacific Northwest National Laboratory, Richland, Washington.

Pasamehmetoglu KO, WL Kubic, and P Sadasivan. 1997. Discussion of Flammable Gas Issues for Project W-320. LA-UR-97-1330 Rev. 1A, Los Alamos National Laboratory, Los Alamos, New Mexico.

Stewart CW, FF Erian, PA Meyer, KP Recknagel, WB Gregory, ZI Antoniak, and DM Pfund. 1997. Monitoring Gas Retention and Slurry Transport During the Transfer of Waste from Tank 241-C-106 to Tank 241-AY-102. PNNL-11627, Pacific Northwest National Laboratory, Richland, Washington.

Whitney PD. 1995. Screening the Hanford Tanks for Trapped Gas. PNL-10821, Pacific Northwest Laboratory, Richland, Washington.

Whitney PD, PA Meyer, NE Wilkins, F Gao, and AG Wood. 1996. Flammable Gas Data Evaluation Progress Report. PNNL-11373, Pacific Northwest National Laboratory, Richland, Washington.

Whitney PD, G Chen, PA Gauglitz, PA Meyer, and NE Miller. 1997. Estimating Retained Gas Volumes in the Hanford Tanks Using Waste Level Measurements. PNNL-11693, Pacific Northwest National Laboratory, Richland, Washington.

Wilkins NE, RE Bauer, and DM Ogden. 1997. Results of Vapor Space Monitoring of Flammable Gas Watch List Tanks. HNF-SD-WM-TI-797 Rev. 2, Lockheed Martin Hanford Corp., Richland, Washington. 


\section{Distribution}

No. of

Copies

Offsite

2 DOE.Office of Scientific and

Technical Information

2 Los Alamos National Laboratory

P.O. Box 1663

Los Alamos, NM 87545

Attn: W. L. Kubic

P. Sadasivan

K575

K575

\section{Onsite}

1 DOE Richland Operations Office

W. Abdul

17 PHMC Team

D.G. Baide

S5-05

J. W. Bailey

S2-48

W. B. Barton

R2-11

R. E. Bauer

S7-14

J. R. Bellomy III

R. R. Bevins
No. of

Copies

D. A. Bragg

K. G. Carothers

S5-05

G. D. Johnson

R2-11

N. W. Kirch

J. A. Lechelt

J. W. Lentsch

W. J. Powell

S7-14

R2-11

R2-11

S2-48

S5-13

R. L. Powers

S5-13

D. A. Reynolds

R2-11

G. R. Tardiff

S5-05

N. E. Wilkins

R2-11

23 Pacific Northwest National Laboratory

J. M. Bates

K7-15

S. Q. Bennett

K7-90

J. W. Brothers

K5-22

G. Chen

K5-12

J. M. Cuta

K $7-15$

F. F. Erian

K7-15

P. A. Gauglitz

K6-28

L. A. Mahoney

P. A. Meyer

C. W. Stewart (8)

P. D. Whitney

K7-15

K7-15

K7-15

K5-12

Information Release (5)

K6-06 